\title{
The influence of the QBO on the propagation of equatorial waves into the stratosphere
}

Article

Published Version

Yang, G.-Y., Hoskins, B. and Gray, L. (2012) The influence of the QBO on the propagation of equatorial waves into the stratosphere. Journal of the Atmospheric Sciences, 69 (10). pp. 2959-2982. ISSN 1520-0469 doi:

https://doi.org/10.1175/JAS-D-11-0342.1 Available at https://centaur.reading.ac.uk/29390/

It is advisable to refer to the publisher's version if you intend to cite from the work. See Guidance on citing.

To link to this article DOI: http://dx.doi.org/10.1175/JAS-D-11-0342.1

Publisher: American Meteorological Society

All outputs in CentAUR are protected by Intellectual Property Rights law, including copyright law. Copyright and IPR is retained by the creators or other copyright holders. Terms and conditions for use of this material are defined in the End User Agreement.

www.reading.ac.uk/centaur 
Central Archive at the University of Reading

Reading's research outputs online 


\title{
The Influence of the QBO on the Propagation of Equatorial Waves into the Stratosphere
}

\author{
GUI-YING YANG \\ National Centre for Atmospheric Science, and University of Reading, Reading, United Kingdom \\ BRIAN HOSKINS \\ University of Reading, Reading, and Grantham Institute for Climate Change, Imperial College, London, United Kingdom
}

LESLEY GRAY

National Centre for Atmospheric Science, Reading, and University of Oxford, Oxford, United Kingdom

(Manuscript received 29 December 2011, in final form 27 April 2012)

\begin{abstract}
The variation of stratospheric equatorial wave characteristics with the phase of the quasi-biennial oscillation $(\mathrm{QBO})$ is investigated using ECMWF Re-Analysis and NOAA outgoing longwave radiation (OLR) data. The impact of the QBO phases on the upward propagation of equatorial waves is found to be consistent and significant. In the easterly phase, there is larger Kelvin wave amplitude but smaller westward-moving mixed Rossby-gravity (WMRG) and $n=1$ Rossby (R1) wave amplitude due to reduced propagation from the upper troposphere into the lower stratosphere, compared with the westerly phase. Differences in the wave amplitude exist in a deeper layer in summer than in winter, consistent with the seasonality of ambient zonal winds. There is a strong evidence of Kelvin wave amplitude peaking just below the descending westerly phase, suggesting that Kelvin waves act to bring the westerly phase downward. However, the corresponding evidence for WMRG and R1 waves is less clear.

In the lower stratosphere there is zonal variation in equatorial waves. This reflects the zonal asymmetry of wave amplitudes in the upper troposphere, the source for the lower-stratospheric waves. In easterly winters the upper-tropospheric WMRG and R1 waves over the eastern Pacific region appear to be somewhat stronger compared to climatology, perhaps because of the accumulation of waves that are unable to propagate upward into the lower stratosphere. Vertical propagation features of these waves are generally consistent with theory and suggest a mixture of Doppler shifting by ambient flows and filtering. Some lower-stratosphere equatorial waves have a connection with preceding tropical convection, especially for Kelvin and R1 waves in winter.
\end{abstract}

\section{Introduction}

Equatorial waves in the lower stratosphere are known to be important in driving the quasi-biennial oscillation (QBO) and the semiannual oscillation in the equatorial stratosphere and are important in stratosphere-troposphere interaction (e.g., Lindzen and Holton 1968; Holton and Lindzen 1972; Hitchman and Leovy 1988; Dunkerton 1997; Baldwin et al. 2001; Fujiwara and Takahashi 2001; Giorgetta et al. 2002; Gray

Corresponding author address: Gui-Ying Yang, Department of Meteorology, University of Reading, Earley Gate, Reading RG6 6BB, United Kingdom.

E-mail: g.y.yang@reading.ac.uk
2010). Recent observational and model studies have revealed more information on the contributions of equatorial waves to the driving of the QBO at different periods (e.g., Ern and Preusse 2009; Kawatani et al. 2010a,b; Alexander and Ortland 2010).

After the first discovery of observational evidence of Kelvin wave and westward-moving mixed Rossbygravity (WMRG) wave in the stratosphere (Yanai and Maruyama 1966; Wallace and Kousky 1968), there have been many subsequent observational studies of equatorial waves in the troposphere and stratosphere, particularly Kelvin and WMRG waves (e.g., Zangvil and Yanai 1980, 1981; Dunkerton 1993; Takayabu 1994; Dunkerton and Baldwin 1995; Wheeler and Kiladis 1999; Wheeler et al. 2000; Straub and Kiladis 2003; Yang et al. 2003; 
Randel and Wu 2005; Tindall et al. 2006; Yang et al. 2007 a,b,c; Alexander et al. 2008; Suzuki and Shiotani 2008; Kiladis et al. 2009; Lott et al. 2009; Alexander and Ortland 2010; Yang et al. 2011). However, there is relatively less observational knowledge of the tropospheric origin of the stratospheric waves, their zonal and vertical propagation, and how the propagation is influenced by ambient flows in the stratosphere. In particular, this is the case for equatorial Rossby waves. In addition, most of the observational studies are based on radiosonde or satellite data, and many of them consider only temperature or trace constituents. These data have one or more shortcomings, such as limited horizontal and vertical coverage, very limited time period, or poor temporal and/or spatial resolution, especially poor vertical resolution that limits the ability to examine the critical-layer interaction responsible for the QBO accelerations. Therefore, the horizontal and vertical structures of the waves may not be well delineated and the frequencies of the waves may suffer from temporal aliasing.

Some studies used analysis datasets without such shortcomings; nevertheless, there can be questions over the techniques used to identify disturbances. In these studies, the basis of the identification of the equatorial wave modes was the theoretical dispersion relation for a variety of specified equivalent depths, or the theoretical phase relationships between variables (e.g., wind components and temperature) that arise from such a framework. However, in the real atmosphere the complicated space-time dependence of the ambient state, the feedback from convective heating organized by the wave, nonlinearities, and nonuniform damping can all be expected to lead to distortion of the theoretical dispersion curves; at the very least there can be an expectation of some Doppler shifting, and perhaps invalidity of the modal separation in the vertical, and hence the concept of equivalent depth. Consequently, different equatorial modes may not, in reality, be well separated in the frequency and zonal wavenumber domain. An example is WMRG and $n=1$ Rossby (R1) waves, which are often in a very close zonal wavenumber-frequency domain, and sometimes merge together, as shown in YHS07c. Also, it is unclear how much of the shallow water theory of equatorial waves can be carried over to the real world.

A less constraining methodology for identifying equatorial waves-which does not assume that the linear adiabatic theory for equatorial waves on a resting atmosphere is directly applicable, and is not limited to a prescribed space-time spectral filter but accounts for Doppler shift automatically — was developed in Yang et al. (2003, hereafter YHS) and is briefly described in the next section. This methodology, which depends on projection of fields onto a set of horizontal basis functions at each level, has been applied in a number of observational studies of convectively coupled equatorial waves using 15-yr European Centre for Medium-Range Weather Forecasts (ECMWF) Re-Analysis (ERA-15) data (Yang et al. 2007a,b,c, hereafter YHS07a,b,c) and has proved useful in the evaluation of the ability of model performance in the simulation of convectively coupled equatorial waves (Yang et al. 2009).

It has been shown in these studies that although dynamical fields are projected separately at each level, they exhibited the general consistency of the space-time structure of the individual wave components identified in different periods, and also of the convection with them. This gives confidence that the methodology was successful in identifying equatorial wave structures and in detecting some important characteristics of them. The methodology is especially useful in identifying and separating some waves that tend to appear together and have similar zonal wavenumbers and frequencies, such as WMRG and R1 waves. Those waves are unlikely to be separated using space-time filtering technique or filtering based on dispersion curves due to Doppler shifting. The methodology is also useful in detecting some uppertropospheric waves that tend to move in the opposite direction to that expected from basic theory because of strong ambient flows. Also, as indicated by a recent study of Gehne and Kleeman (2012), who used parabolic cylinder functions to project 20 years of brightness temperature and dynamical data onto different wave modes and then analyzed their space-time spectra, the projection technique may help to reduce background noise and distinguish equatorial wave modes from other modes, such as extratropical waves.

Particularly relevant to the current study is that this approach has recently been used to analyze multilevel 40-yr ECMWF Re-Analysis (ERA-40) data for two different half years (May-October in 1992 and 1993) to investigate the behavior of the equatorial waves under opposite phases of the QBO (Yang et al. 2011, hereafter YHS11). The study provided an unprecedented and detailed view of 3D structures and of zonal and vertical propagation of equatorial waves, including the $\mathrm{R} 1$ wave in opposite QBO phases. Consistent with expectation, it was found that in 1992, an easterly QBO phase in the lower stratosphere, there was more upward propagation of the Kelvin wave compared with 1993, a westerly QBO phase, but less of the WMRG and R1 waves and vice versa. It was shown that, for both years, waves in the lower stratosphere have smaller zonal wavenumber, shorter period, faster phase speed, and shorter vertical wavelength than those in the upper troposphere, and that waves show an upward group velocity and downward phase speed in the lower stratosphere. In the year when 
the phase of the QBO is not favorable for particular waves to propagate, their phase speed in the lower stratosphere is larger than in the alternate phase, an indication of Doppler shifting by the ambient flow and suggestive of a filtering of the slow waves. These results are generally consistent with the propagation theory of equatorial waves.

In YHS11 the analysis was only for two summers of ERA-40 data. In this study we analyze 32 years of the newer interim ECMWF Re-Analyisis (ERA-Interim) data for 1979-2010, and also the whole ERA-40 reanalysis data for 1979-2002, for both extended boreal summer and winter. The main aim of the study is not just to analyze more years of data, but to provide a systematic/robust comprehensive view of the behavior of equatorial waves in different QBO phases and to examine the extent of interannual variability of equatorial waves associated with different QBO phases in the upper troposphere and lower stratosphere. The present analysis also reveals some interesting features not seen in the previous analysis.

The outline of this paper is as follows. Section 2 describes the data and methodology. Section 3 presents the propagation theory and selection of easterly and westerly QBO-phase years. Wave amplitudes, including their power spectra and zonal and vertical variations, are shown in section 4. Section 5 shows composite zonal and vertical propagation features of the waves. Section 6 presents the connection of waves with tropical convection. Some conclusions and a discussion are given in section 7 .

\section{Data and method}

Data used in this study are the ERA-Interim data and National Oceanic and Atmospheric Administration (NOAA) interpolated daily outgoing longwave radiation (OLR) for the period from 1979 to 2010. Interpolated OLR data are provided by the NOAA's Office of Oceanic and Atmospheric Research Earth Systems Research Laboratory, Physical Sciences Division (NOAA/OAR/ ESRL PSD), Boulder, Colorado (available online at http://www.esrl.noaa.gov/psd/) (Liebmann and Smith 1996). ERA-Interim is the latest global atmospheric reanalysis produced by the ECMWF. Multilevel ERAInterim 6-hourly data are stored with a horizontal resolution of about $0.7^{\circ}$ and at 37 pressure levels from 1000 to $1 \mathrm{hPa}$. Detailed information about the ERA-Interim data can be found in Dee et al. (2011). The dynamical fields used to analyze equatorial waves are 6-hourly horizontal winds $(u, v)$ and geopotential $Z$. The wind fields used in this study are generally considered to be of high quality because of their strong dependence on good satellite data. For comparison, the same analysis has been performed on the ERA-40 data for the satellite period,
1979-2002. This has a lower resolution, about $1.125^{\circ}$ in the horizontal and 23 pressure levels from 1000 to $1 \mathrm{hPa}$.

The methodology to identify equatorial waves developed in YHS does not assume that the linear adiabatic theory for equatorial waves on a resting atmosphere is directly applicable; in particular, the vertical structures and dispersion relations of theoretical equatorial waves are not imposed. As described in YHS and YHS07a, potential equatorial waves are identified by projecting the dynamical fields at each pressure level onto the horizontal structures given by equatorial wave theory. The parabolic cylinder functions that describe the horizontal structures of theoretical equatorial waves were used as basis functions for projecting the wind and height fields, and this was done independently at each pressure level.

Before projection, the dynamical fields are first separated into eastward- and westward-moving components using a space-time spectral analysis. The data are filtered in a domain of zonal wavenumber $k$ from \pm 2 to \pm 10 and period from 2 to 30 days that contains most equatorial waves. This filter includes a broader spatialtemporal domain than that which fits the usual shallow water dispersion curves and is necessary to represent the structures in the ERA data. Wavenumber 1 is not included in the analysis because of problems with the ERA data, as also discussed in YHS. Also, westwardmoving zonal wavenumber 1 in geopotential height is not equatorially trapped and is not relevant to this study [also see Fig. 4.10 in Andrews et al. (1987), p. 171].

Meridional wind $v$ is projected directly onto the parabolic cylinder functions, and, as in Gill (1980), the variables $q=\alpha Z+u$ and $r=\alpha Z-u$ are also projected independently onto the different modes. Parabolic cylinder functions $D$ take the form

$$
D_{r}\left(y / y_{0}\right)=\exp \left[-\left(y / 2 y_{0}\right)^{2}\right] P_{r}\left(y / y_{0}\right)
$$

where $P_{r}$ is a polynomial of degree $r$ and $y_{0}$ is the latitudinal trapping scale.

Guided by basic equatorial wave theory and observational analyses, the parabolic cylinder function series expansions are organized and described as follows:

$$
\begin{gathered}
q=q_{0} D_{0}+q_{1} D_{1}+\sum_{n=1}^{n=\infty} q_{n+1} D_{n+1}, \\
v=0+v_{0} D_{0}+\sum_{n=1}^{n=\infty} v_{n} D_{n}, \\
r=\begin{array}{c}
0 \\
0
\end{array} \quad+\sum_{n=1}^{n=\infty} r_{n-1} D_{n-1} . \\
\begin{array}{c}
\uparrow \\
n=-1 n=0 \quad
\end{array} \quad n=1,2 \ldots
\end{gathered}
$$


For our projection of the data at each level we will consider the $n=-1$ field $\left(q_{0}\right)$ and refer to the eastward component as the Kelvin wave. Together the $n=0$ fields $\left(q_{1}\right.$ and $v_{0}$ ) will be considered to describe the mixed Rossby-gravity wave, with the eastward component referred to as EMRG and the westward component as WMRG. In theory, the $n=1$ fields $\left(q_{2}, v_{1}, r_{0}\right)$ describe three waves, the westward-moving Rossby wave, R1, and the eastward- and westward-moving gravity waves. As will be shown later, high-frequency gravity waves are found to be weak so that the westward $n=1$ structure is considered to represent the R1 wave.

In YHS, $y_{0}$ is predetermined by a best fit of the tropospheric $v$ field in the latitude belt $20^{\circ} \mathrm{N}-20^{\circ} \mathrm{S}$ and it was found that the best fit for $y_{0}$ is $6^{\circ}$. To examine if $y_{0}$ is different in different years and, in particular, if it is sensitive to the ambient flows in different QBO phases in the stratosphere, a similar analysis has been performed for 23 years of ERA-40 data for $v, q$, and $r$. As in YHS the best-fit $y_{0}$ is chosen so as to minimize analysis errors for a truncated representation. The time-mean analysis error is defined as follows:

$E_{N}\left(x_{i}, y_{j}, y_{0}\right)=\frac{\sum_{k}\left[\tilde{v}\left(x_{i}, y_{j}, t_{k}\right)-\sum_{n=0}^{N} \tilde{v}_{n}\left(x_{i}, t_{k}\right) D_{n}\left(y_{j} / y_{0}\right)\right]^{2}}{\sum_{k}\left[\tilde{v}\left(x_{i}, y_{j}, t_{k}\right)-\bar{v}\left(x_{i}, y_{j}\right)\right]^{2}}$,

where $\left(x_{i}, y_{j}, t_{k}\right)$ is a space-time grid point of the data; $\tilde{v}$ represents one of the variables $v, q$, or $r$ that is filtered to give its eastward- or westward-moving component in the specified zonal wavenumber-frequency domain $\{k, \omega\}$; $\tilde{v}_{n}$ is the coefficient of $\tilde{v}$ projected onto the $n$th parabolic cylinder function $D_{n}\left(y / y_{0}\right) ; \bar{v}$ is the seasonal mean of $\tilde{v}$ and hence the denominator of Eq. (3) is the variance of $\tilde{v}$; and $N$ is the truncation limit of the series.

We calculate errors in the fit of westward-moving $v$ and eastward-moving $q$ and $r$ as a function of $y_{0}$ and truncation values $N$ to examine the best fit for westwardmoving and eastward-moving waves. As in YHS (their Fig. 6), it is found that the gravest modes $n=0-4$ dominate. Figures $1 \mathrm{a}$ and $1 \mathrm{~b}$ shows errors in the fit of westward-moving $v$ as a function of $y_{0}$ for $N=4$ truncation, at 100 and $50 \mathrm{hPa}$, respectively, for each easterly and westerly QBO summer defined in the next section (see Fig. 2 below). There is a distinct minimum at $y_{0}=6^{\circ}$ in each case. At $100 \mathrm{hPa}$, the minimum error is below $5 \%$, smaller than that in the troposphere $(10 \%-15 \%)$ and similar to that for $200 \mathrm{hPa}$ in YHS. It is interesting that at $100 \mathrm{hPa}$ the errors are similar for easterly and westerly seasons, but at $50 \mathrm{hPa}$ there is a clear difference between the two phases, with errors in the westerly phase
( $4 \%$ at $y_{0}=6^{\circ}$ ) being consistently smaller than those in the easterly phase $\left(6 \%\right.$ at $\left.y_{0}=6^{\circ}\right)$. This suggests that in the westerly phase WMRG and Rossby waves make a larger contribution to the variability of meridional wind in the lower stratosphere. As will be shown later this is in agreement with that in the westerly phase there is more westward-moving waves propagating into the lower stratosphere. It is also evident that the best-fit $y_{0}$ is not sensitive to the phase of the QBO. The error difference at $50 \mathrm{hPa}$ between different QBO phases is also seen at 70 and $30 \mathrm{hPa}$ but with the difference in the former being smaller.

Figures 1c-f show errors in the fit of eastward-moving $q$ and $r$. It is seen that for $N=4$ there is also a minimum error at $y_{0}=6^{\circ}$. However, at $50 \mathrm{hPa}$, the minimum is not as sharp as that for $v$. At $100 \mathrm{hPa}$ the minimum error in $q$ and $r$ is $10 \%-12 \%$, larger than that for $v$. In contrast to westward-moving $v$, errors in $q$ and $r$ at $50 \mathrm{hPa}$ are consistently smaller in the easterly phase than those in the westerly phase, with errors in $q$ being smaller than in $r$. This is also consistent with the idea that eastward-moving waves, such as the Kelvin wave, can propagate more readily into the lower stratosphere in the easterly phase.

As results for winter are very similar (not shown), in this study $y_{0}$ is chosen as $6^{\circ}$ as it was in YHS. Gehne and Kleeman (2012), who analyzed 20 years of brightness temperature and dynamical data, also found an optimum $y_{0}=6^{\circ}$. It could be argued that, according to the $q$ error at $50 \mathrm{hPa}$, any value for $y_{0}$ between, say, $5^{\circ}$ and $8^{\circ}$ could be relevant. However, in section $5 \mathrm{c}$ it will be shown that the results obtained are not sensitive to the choice of the trapping scale.

In the basic theory the trapping scale is related to the gravity wave speed $c_{e}$, and the equivalent depth $h\left[c_{e}=\right.$ $\left.(g h)^{1 / 2}\right]$, by

$$
y_{0}=\left(c_{e} / 2 \beta\right)^{1 / 2}=(g h)^{1 / 4} /(2 \beta)^{1 / 2} .
$$

Thus

$$
h \sim y_{0}^{4} \quad \text { and } \quad c_{e} \sim y_{0}^{2} .
$$

The powers of $y_{0}$ in these expressions indicate that the horizontal structure functions used here may be much less sensitive than the vertical structures and less sensitive than the phase speeds. We allow these properties to emerge from the data. However, in equatorial wave theory, $\alpha$ is taken to be equal to $c_{e}^{-1} \sim y_{0}^{-2}$, and so there could be some sensitivity in the current analysis technique in the separation of $u$ and $Z$ into $q$ and $r$. It will be shown below that analysis using different values for $y_{0}$ shows that the structures and phase speed of equatorial waves are not in fact sensitive to the choice of $y_{0}$. 

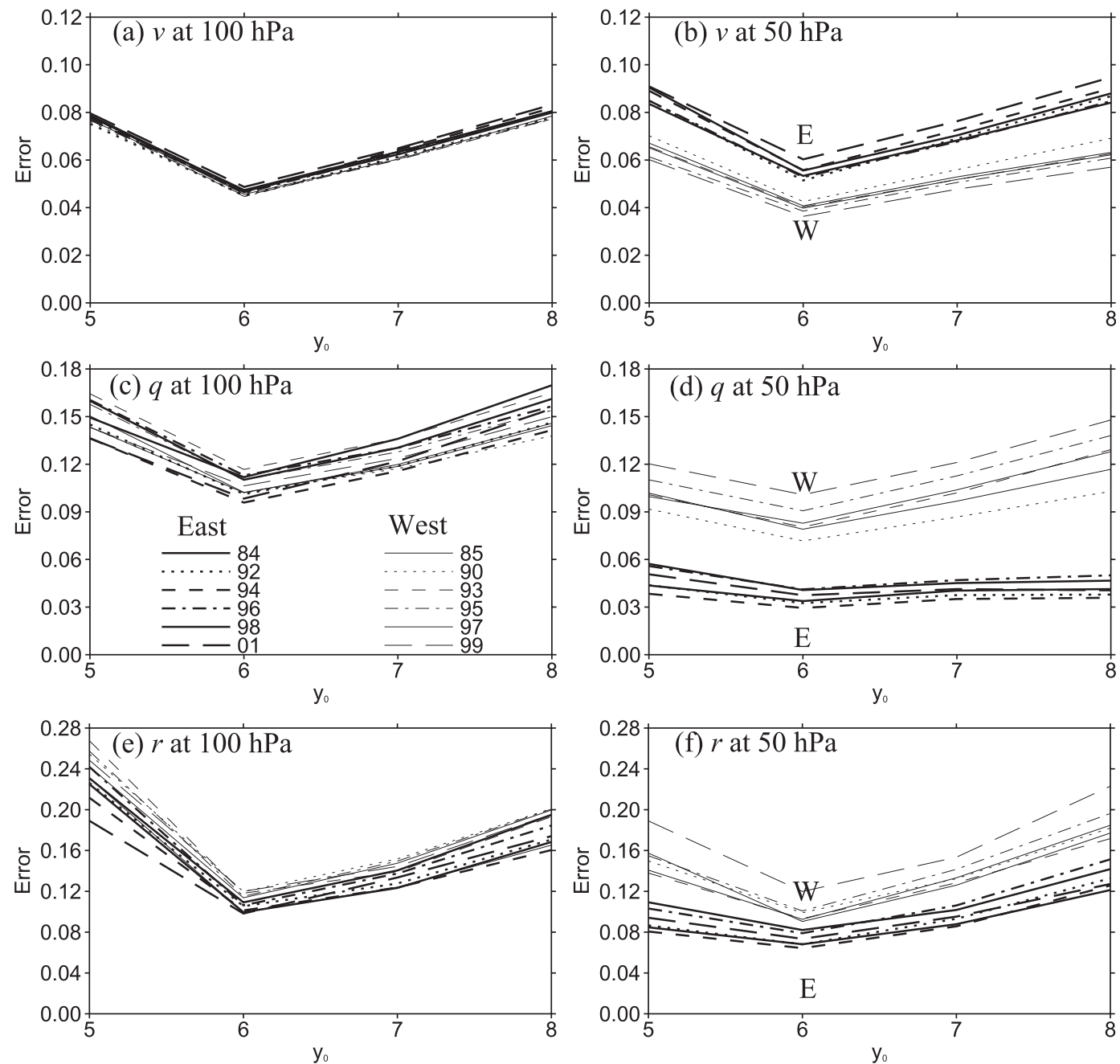

FIG. 1. Space-time mean analysis error in the fit of (a),(b) westward-moving $v$, (c),(d) eastward-moving $q$, and (e),(f) eastward-moving $r$ at (left) 100 and (right) $50 \mathrm{hPa}$, as a function of $y_{0}$ for a truncation $N=4$ in the series defined by Eq. (3). Only summers are shown and those with an easterly (westerly) QBO phase are indicated by thick (thin) lines.

The wave amplitudes change only slightly, except for the Kelvin wave. The latter finding is perhaps consistent with the large theoretical sensitivity of $\alpha$ to $y_{0}^{-2}$.

Since results from ERA-Interim and ERA-40 are very similar, most results will be shown for ERA-Interim; unless specified, the figures will be for this dataset.

\section{Propagation theory and phases of the QBO}

Details of the theory of the propagation of equatorial waves can be found in Andrews et al. (1987), and some aspects of the theory including equatorial R1 have been summarized in YHS11. Here only a brief summary will be given.

As in Andrews et al. (1987), the zonal and vertical propagation of equatorial waves can be investigated by considering solutions to the adiabatic, frictionless equations of motion on an equatorial $\beta$-plane linearized about a time mean zonal flow $U(z)$ using the slow-variation Wentzel-Kramers-Brillouin-Jeffries (WKBJ) approximation. Using standard notation, the horizontal and vertical velocity $\left(u^{\prime}, v^{\prime}, w^{\prime}\right)$ and geopotential $Z$ fields can be taken to be of the form

$$
e^{z / 2 H} A(y) \exp i(k x+m z-\omega t)
$$

where the amplitude $A$ and the vertical wavenumber $m$ are slowly varying function of $z$. Waves with zonal phase speed $c$ can propagate vertically only in zonal winds that satisfy

$$
c-U(z)>0 \text { for Kelvin waves and }
$$




$$
-\beta / k^{2}<c-U(z)<0
$$

for WMRG and Rossby waves.

Therefore Kelvin waves only exist in regions of easterly or weak westerly winds in which they have an eastward phase speed with respect to the ambient flow. Westwardmoving WMRG and R1 waves only exist in regions of westerly or weak easterly, in which they have a westward phase speed with respect to the ambient flow. However, the magnitude of the zonal flow is limited so that their westward phase speed relative to the flow is not larger than $\beta / k^{2}$. Therefore it is expected that an easterly phase is favorable for Kelvin waves propagating upward into the lower stratosphere, whereas a westerly phase is favorable for upward propagation of westward-moving WMRG and R1 waves.

For the different waves, the vertical wavenumber is

Kelvin wave: $m(z)=\mp \frac{N}{c-U(z)}$,

WMRG wave: $m(z)= \pm \frac{N\left\{\beta / k^{2}+[c-U(z)]\right\}}{[c-U(z)]^{2}}$

$$
\text { R1 wave: } m(z)= \pm \frac{N \beta(n+1 / 2-\Delta)}{k^{2}[c-U(z)]^{2}} \text {, }
$$

where $\Delta=\left[(n+1 / 2)^{2}+\left\{k^{2}[c-U(z)] / \beta\right\}\left(1+\left\{k^{2}[c-\right.\right.\right.$ $U(z)] / \beta\})]^{1 / 2}$. The vertical group velocity is

$$
\begin{aligned}
\text { Kelvin wave: } c_{g z}(z) & = \pm \frac{k[c-U(z)]^{2}}{N}, \\
\text { WMRG wave: } c_{g z}(z) & =\mp \frac{k[c-U(z)]^{3}}{N\left[2 \beta / k^{2}+c-U(z)\right]},
\end{aligned}
$$

For these waves, vertical group velocity increases with $|c-U|$ and becomes small as $c$ approaches $U$ (a critical level). As each wave approaches a critical line $U(z)=c$, its vertical wavelength and group velocity tend to zero. The asymptotic behavior as $c$ tends to zero was detailed in YHS11. As their vertical group velocity and wavelength decrease the waves become more susceptible to dissipation. Therefore waves with larger magnitudes of $c$ can propagate upward more readily.

In the basic theory, the trapping scale $y_{0}=\left(c_{e} / 2 \beta\right)^{1 / 2}$ can be related to the vertical wavelength. It should be noted that $c_{e}$ is the eigenvalue of the vertical structure equation $\left[c_{e}=(g h)^{1 / 2}\right]$. It is equal to the intrinsic phase speed only for the Kelvin wave. For the Kelvin wave, from Eq. (8) the vertical wavelength $D=2 \pi / m=2 \pi c_{i} / N$, where $c_{i}=c-U=c_{e}$. Then

$$
y_{0}=\left(c_{e} / 2 \beta\right)^{1 / 2}=(N D / 4 \pi \beta)^{1 / 2} .
$$

This equation gives that when the wave propagates into the lower stratosphere, as $D$ decreases, $y_{0}$ also decreases. For $N=2.2 \times 10^{-2} \mathrm{~s}^{-1}$ in the lower stratosphere, $\beta=$ $2.3 \times 10^{-11} \mathrm{~m}^{-1} \mathrm{~s}^{-1}$, and then $y_{0}=6.9^{\circ}, 6.3^{\circ}, 5.9^{\circ}$, and $5.4^{\circ}$ (corresponding to 764, 715, 661, and $604 \mathrm{~km}$ ) for $D=8,7,6$ and $5 \mathrm{~km}$, respectively. This suggests that $y_{0}$ may be different in different QBO phases because of the change in $D$. Nevertheless, as will be shown in section 5 , the typical $D$ of the Kelvin wave in the lower stratosphere is $8 \mathrm{~km}$ in the easterly phase and $6 \mathrm{~km}$ in the westerly phase, corresponding to predicted $y_{0}$ of $6.9^{\circ}$ and $5.9^{\circ}$, respectively. These values are close to the $6^{\circ}$ used in this study and, as will be shown in section $5 \mathrm{c}$, the analysis is not sensitive to $y_{0}$.

Figure 2 a shows the monthly mean equatorial $\left(5^{\circ} \mathrm{N}-\right.$ $\left.5^{\circ} \mathrm{S}\right)$ zonal mean zonal winds in the period 1979-2010 between 100 and $5 \mathrm{hPa}$. In this stratospheric region, the variability of the equatorial zonal winds are dominated by the QBO, which is seen as downward-propagating easterly and westerly wind regimes, with a variable period near 26 months (Above $5 \mathrm{hPa}$, the semiannual oscillation is dominant). Westerly shear zones show more regular and rapid downward propagation than easterly shear zones, consistent with other studies (e.g., Baldwin et al. 2001). It is seen that although the QBO is not an exactly biennial oscillation, there is a tendency for the onset of both easterly and westerly wind regimes at $50 \mathrm{hPa}$ to occur mainly during boreal late spring, as indicated by Dunkerton (1990) and Baldwin et al. (2001). Because of this seasonal preference in the QBO phase reversal and also the large seasonal variability of equatorial waves, for the analysis here the year is split into two 6-month periods, an extended boreal summer (May-October) and 

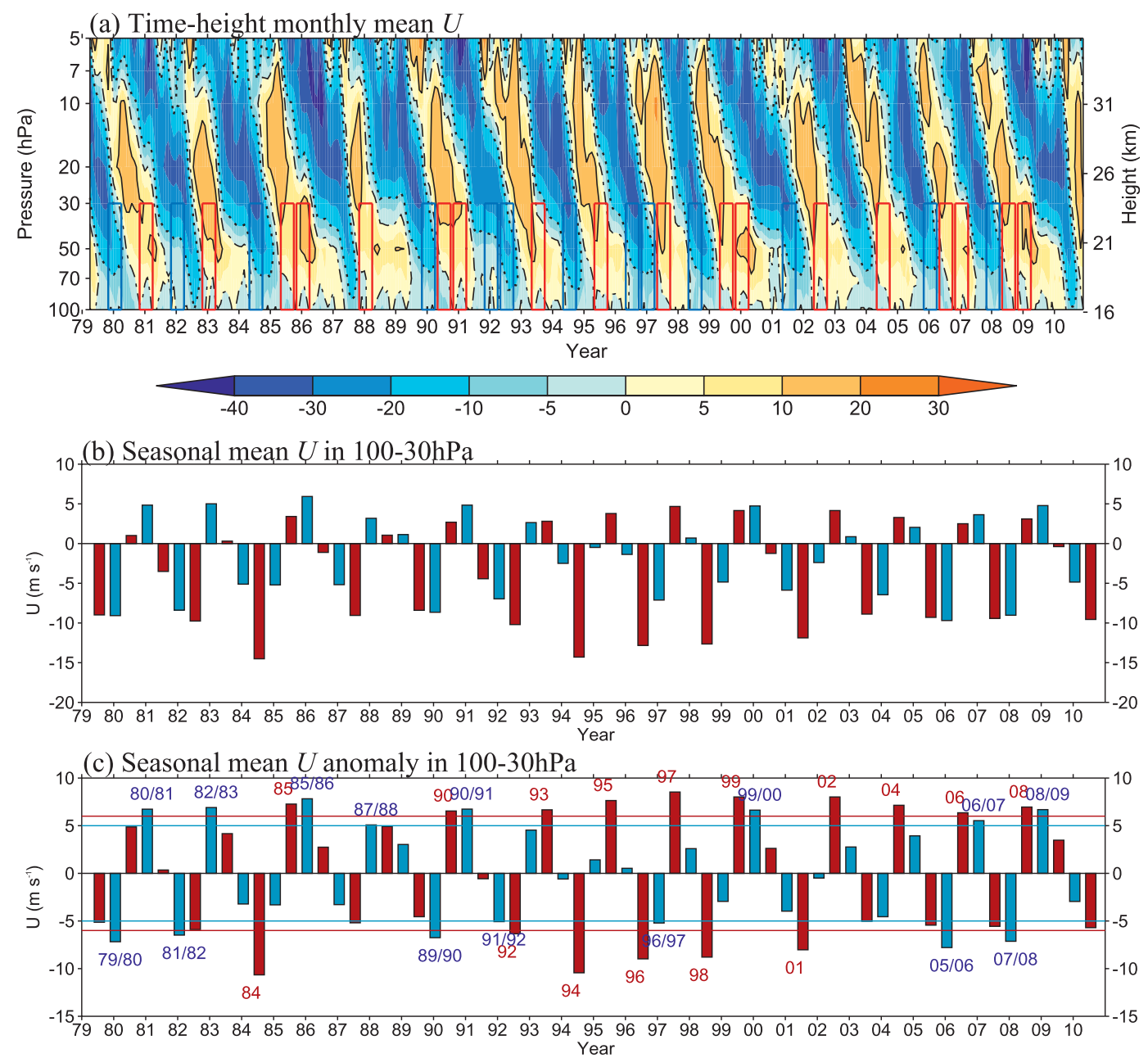

FIG. 2. (a) Time-height cross section of the monthly mean equatorial $\left(5^{\circ} \mathrm{N}-5^{\circ} \mathrm{S}\right)$ zonal mean $U\left(\mathrm{~m} \mathrm{~s}^{-1}\right)$ for 1979 2010. Blue (red) boxes indicate the easterly (westerly) phase in lower-stratospheric winds, as defined in (c). (b) Seasonal mean lower-stratospheric (30-100 hPa) equatorial $U$ in the "summer" season (May-October; red) and in "winter" (November-April; blue). (c) As in (b), but for anomalies with respect to the average seasonal cycle. Two red and blue lines indicate threshold $U$ anomalies of \pm 6 and $\pm 5 \mathrm{~m} \mathrm{~s}^{-1}$, used to define QBO phases in summer and winter, respectively. The numbers indicate the years for easterly and westerly seasons defined for summer and winter.

winter (November-April). Hereafter these will be referred to as summer and winter.

Figure $2 \mathrm{~b}$ shows seasonal mean zonal winds averaged over the lower stratosphere $(30-100 \mathrm{hPa})$. First, it is seen that easterly winds are stronger than westerly winds, which is a commonly observed feature (Baldwin et al. 2001). Second, easterly winds in summer are stronger than in winter. The average wind speed is $-3.9 \mathrm{~m} \mathrm{~s}^{-1}$ in summer and $-1.9 \mathrm{~m} \mathrm{~s}^{-1}$ in winter. Consistent with this, the easterly phase appears strongest in summer and the westerly phase stronger in winter. In Fig. $2 c$ the seasonal means have been removed and it is seen that interannual variability is slightly larger in summer. Reflecting this, easterly and westerly seasons will be defined to be those in which the amplitude of seasonal mean $U$ anomaly is larger than $6 \mathrm{~m} \mathrm{~s}^{-1}$ in summer and $5 \mathrm{~m} \mathrm{~s}^{-1}$ in winter. The two wind thresholds are indicated by the red and blue lines, respectively. In 1979-2010, there are 6 easterly summers $(1984,1992,1994,1996,1998$ and 2001), 10 westerly summers $(1985,1990,1993,1995$, 1997, 1999, 2002, 2004, 2006 and 2008), 7 easterly winters $(1979 / 80,1981 / 82,1989 / 90,1991 / 92,1996 / 97,2005 /$ 06, and 2007/08) and 8 westerly winters (1980/81, 1982/ 83, 1985/86, 1987/88, 1990/91, 1999/2000, 2006/07 and 2008/09). These seasons are indicated by the dates associated with them in Fig. 2c. They are also shown as solid red and blue boxes in Fig. 2a, for easterly and westerly phases, respectively. 


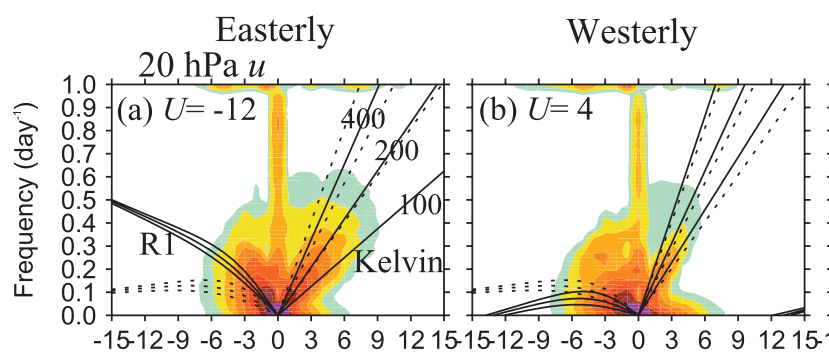

Non-classified

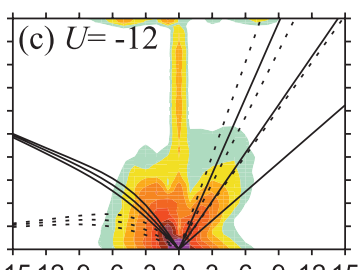

Easterly -Westerly

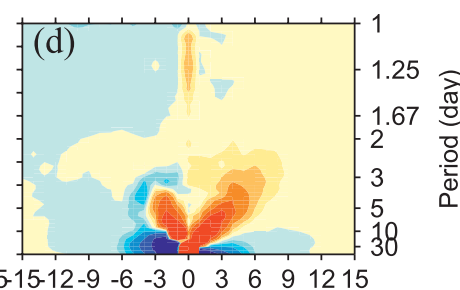

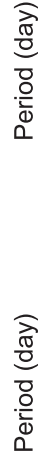

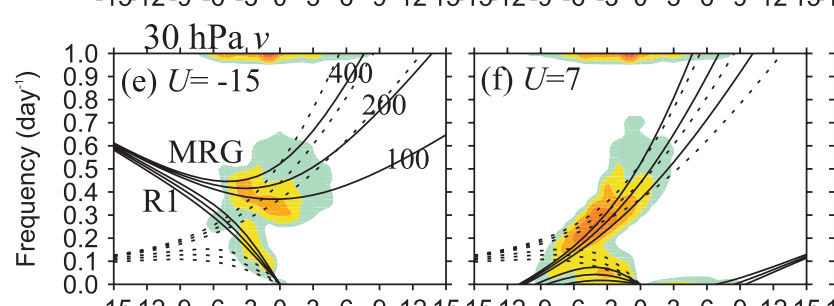

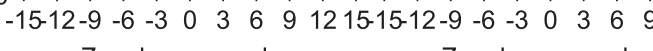

Zonal wavenumber

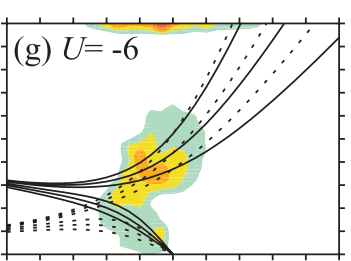

Zonal wavenumber

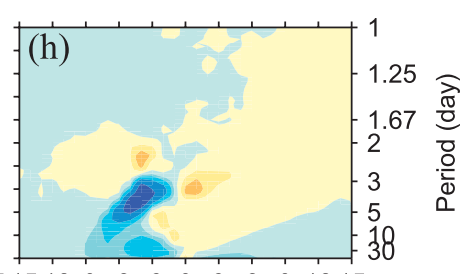

Zonal wavenumber

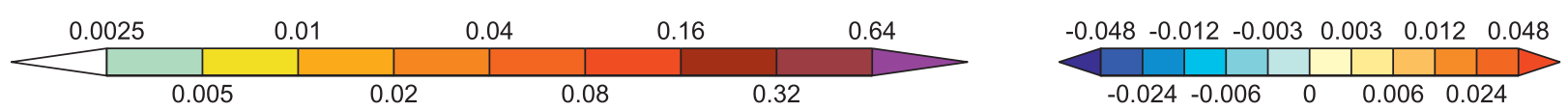

FIG. 3. Zonal wavenumber-frequency raw power spectra for (a)-(d) $u$ at $20 \mathrm{hPa}$ and (e)-(h) $v$ at $30 \mathrm{hPa}$, averaged for all easterly, westerly, and nonclassified years, and the difference between the easterly and westerly phases. The power has been averaged over $15^{\circ} \mathrm{N}-$ $15^{\circ} \mathrm{S}$. Superimposed lines are the two sets of dispersion curves for the equivalent depths of 100,200 , and $400 \mathrm{~m}$, with solid lines including a Doppler shift by the background winds indicated in each panel $\left(\mathrm{m} \mathrm{s}^{-1}\right)$, and dotted lines for the resting atmosphere. The winds in the former are obtained by weighted winds in a layer from $70 \mathrm{hPa}$ up to the level presented. For the 70-, 50-, 30-, and 20-hPa levels the weights

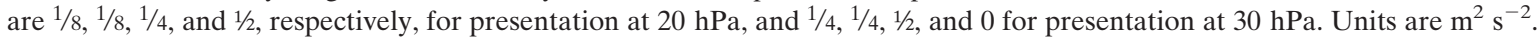

\section{Variability of equatorial waves}

To examine the overall variability of tropical horizontal winds, their space-time power spectra will be discussed in section 4a. Following this, the horizontal winds will be separated into the different wave modes, and their amplitudes and the zonal and vertical variations of these amplitudes will be analyzed in sections $4 \mathrm{~b}-\mathrm{d}$.

\section{a. Power spectra of tropical winds}

Spatial-time power spectral analysis is performed for the 32-yr data in 1979-2010 to investigate the overall variability of tropical horizontal winds. Since Kelvin waves are associated with eastward-moving $u$, and WMRG and R1 waves with westward-moving $v$, we first analyze power spectra for tropical $u$ and $v$ at each latitude and average them over $15^{\circ} \mathrm{N}-15^{\circ} \mathrm{S}$. Figure 3 shows the raw power spectra of $u$ and $v$ in the lower stratosphere, averaged for all easterly (6 summer and 7 winter), westerly (10 summer and 8 winter), and other unclassified seasons (16 summer and 16 winter). The differences between the easterly and westerly phases are also shown. Included also are two sets of theoretical dispersion curves for $U \neq 0$ (solid lines) and $U=0$ (dotted lines) with various equivalent depths. The former takes account of Doppler shifting by typical background winds in the different phases as indicated in each panel.

It is seen that equatorial wave signals are evident even in the raw spectra. These wind power spectra peak on preferred space and time scales that are remarkably consistent with the theoretical dispersion curves for various equivalent depths $h$, fitting better to the Doppler shifted curves. For the Kelvin wave, the central $h$ for $U=$ 0 is $100 \mathrm{~m}$ for the easterly phase and $200 \mathrm{~m}$ for the westerly phase. However, when Doppler shifting is taken into account (solid lines) the Kelvin wave shows a consistent range of $h$ between 100 and $400 \mathrm{~m}$ with a central $h$ about $200 \mathrm{~m}$ for both phases. For $v$ spectra in the westerly and nonclassified phases, a central $h$ of $200 \mathrm{~m}$ for $U=0$ can be seen. However, for $v$ in the easterly phase, there seems to be no optimum $h$ related to $U=0$ because of the power spectra being significantly Doppler shifted.

The Kelvin-like wave, seen in the eastward-moving $u$, is stronger in the easterly phase (Fig. 3a) than in the westerly phase (Fig. 3b), as highlighted in the differences shown in Fig. 3d. In contrast, the WMRG-like signal seen in westward-moving $v$ is much stronger in the westerly phase (Fig. 3f) than in the easterly phase (Fig. 3e). A signal is also seen here in the region of $\mathrm{R} 1$ wave dispersion curves and this is also stronger in the westerly phase than in the easterly phase. It is encouraging that 


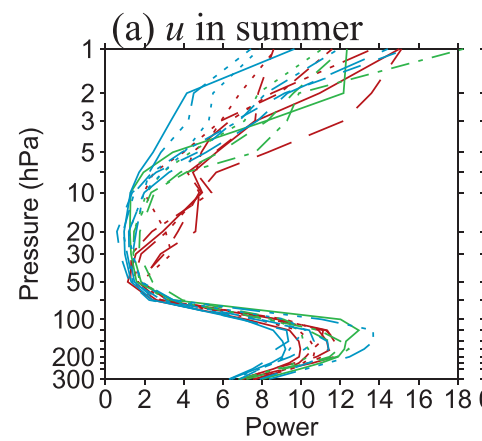

(b) $v$ in summer.
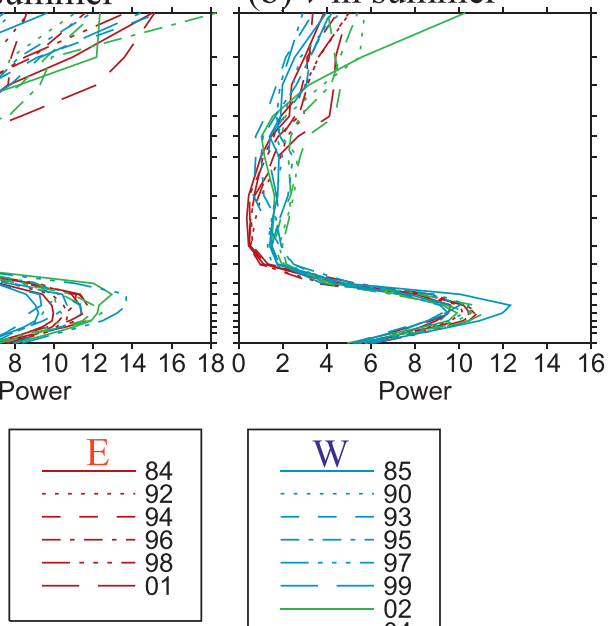

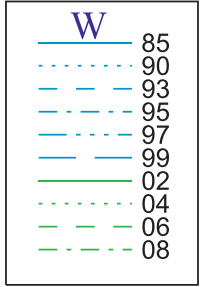

(c) $u$ in winter
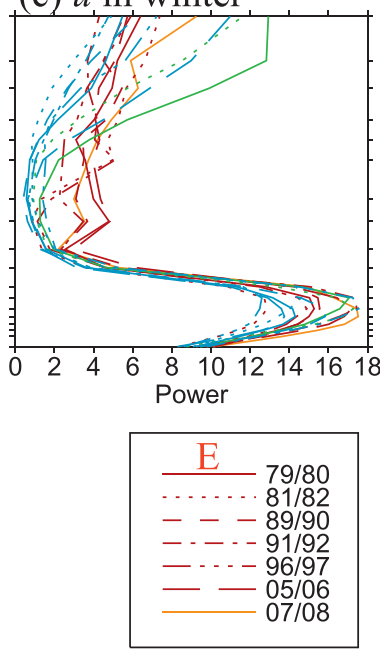

(d) $v$ in winter
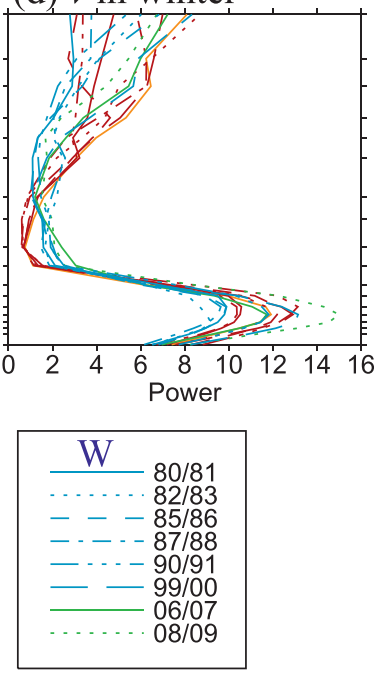

FIG. 4. Vertical profiles of power spectra of tropical (a),(c) eastward-moving $u$ and (b),(d) westward-moving $v$ over the domain of $k$ from 2 to 10 and period from 2 to 30 days, in each easterly (red or orange lines) and westerly (blue or green lines) in (a),(b) summer and (c),(d) winter. Units are $\mathrm{m}^{2} \mathrm{~s}^{-2}$.

the intensity of the power spectra for the nonclassified years (with neutral or weaker winds in the lower stratosphere) (Figs. 3c,g), is found to be between those for the easterly and westerly phases.

Doppler shifting on dispersion curves gives $\omega=\omega_{0}+$ $k U\left(\omega_{0}\right.$ is the frequency at $\left.U=0\right)$. The degree of shift can be estimated by considering the zero-frequency $x$ axis tilted to become $k U$. For $U=30 \mathrm{~m} \mathrm{~s}^{-1}$ and zonal wavenumber 15 , the frequency change is about 1.0 day $^{-1}$, so that the tilted $x$ axis hits the edge of the plot. However, the zero-wavenumber $y$ axis is unaffected, and so the dispersion curves are warped. For $U<0$ eastwardmoving waves are shifted to lower frequency and westward-moving waves are shifted to higher frequency, and vice versa for $U>0$ where lower-frequency and larger wavenumber Rossby waves can be shifted more readily to the opposite quadrant. More detailed Doppler shifting of dispersion curves can be found in YHS07b (their Fig. 7) and Hoskins and Yang (2000, their Fig. 3).

The Kelvin wave-like signal is concentrated at a higher frequency in the westerly phase than in the easterly phase, and the reverse is apparent for the WMRG- and R1-like signals, probably indicative of a mixture of Doppler shifting and filtering of the slower waves in their upward propagation. Both mechanisms would lead to the spectral distributions in the lower stratosphere differing significantly from those in the upper troposphere, as found in YHS11.

In both phases tropical $u$ also shows strong power at zonal wavenumber $k=0$ and also in the westward-moving component. The former is associated with the zonal mean zonal winds and the latter may be related to westwardmoving equatorial waves. On the other hand, power spectra for $v$ are dominated by westward-moving component, although there is some power around $k=0$ and small positive $k$, which indicates signs of EMRG-like waves.

The lower-frequency bands (periods $>10$ days) contain more power in the westerly phase both for eastward- and westward-moving components and for $u$ and $v$ fields, as is clearly seen in the difference plots (Figs. 3d,h). This is consistent with Doppler shifting: westerly winds would shift the westward-moving waves to a lower frequency region, and conversely for easterly winds. Also in the westerly phase, westward-moving waves with very low frequency, such as Rossby waves, can be Doppler shifted to move eastward, as indicated by the dispersion curve for the R1 wave (Fig. 3f) and found in YHS and YHS07a,b,c.

Figure 4 gives vertical profiles of power spectra for each easterly and westerly summer and winter, averaged over eastward and westward domains ( $k$ from \pm 2 to \pm 10 and period from 2 to 30 days), which contain most of the power seen in Fig. 3. Although the wave amplitudes at tropopause level are quite similar in years in the different phases, significant differences are seen in the stratosphere both in summer and winter. In each case, eastwardmoving $u$, mainly associated with Kelvin-like waves, is consistently stronger in the easterly years than in the westerly years in most of the stratosphere. In contrast, in each case westward-moving $v$, dominated by WMRG and 
R1-like waves, exhibits more power in the westerly years than in the easterly years, but the difference between the two phases occurs in a relatively shallower layer in the lower stratosphere than for the eastward-moving $u$. The power of the eastward $u$ at $20 \mathrm{hPa}$ in the westerly phase and the power of the westward-moving $v$ at $50 \mathrm{hPa}$ in the easterly phase is less than $50 \%$ of that in the other phase. In the lower stratosphere, power spectra for the nonclassified years are between the easterly and westerly phase years (not shown).

There is some interannual variability in the upper troposphere that appears to be associated with ENSO. For instance, in summer season, the strongest and weakest power of eastward-moving $u$ in the upper troposphere occur, respectively, in 1997 (El Niño) and 1999 (La Niña) (Fig. 4a). This will be analyzed further in a later paper. The strongest amplitude for the $v$ spectrum in the 1985 summer is consistent with that found in Randel (1992).

Since in the filtering domain used here zonal wavenumbers $k$ range from \pm 2 to \pm 10 and periods from 2 to 30 days, gravity waves are negligible, and the EMRG signal is weak, the focus will be on the remaining waves, which will be referred to as Kelvin, WMRG, and R1.

\section{b. Monthly wave amplitude}

The power spectral analysis has shown that variability associated with tropical winds in the lower stratosphere is consistently different in the two phases of the QBO. To further separate the variability associated with different equatorial wave modes, the tropical winds and height fields at each level are projected into various wave modes using the methodology outlined in section 2 . Figure 5 shows time-height plot of monthly zonal mean standard deviation of the Kelvin, WMRG, and R1 waves in the stratosphere, together with the zonal mean ambient zonal winds. Kelvin wave amplitude is measured by the equatorial $u$ of the Kelvin wave component and WMRG and R1 waves are measured by the equatorial and offequatorial $v$, respectively, of the relevant wave component. Note that, because the horizontal structures are those of the specified basis function used for projection, the pictures for a particular wave are independent of the latitude chosen and only the contour interval would change.

It is seen that there is a remarkable consistency of background winds $\left(-10,0\right.$, and $10 \mathrm{~m} \mathrm{~s}^{-1}$ contours plotted) and wave amplitudes. In Fig. 5a, Kelvin waves are consistently stronger in areas of easterly winds than in westerly winds. In contrast, in Figs. $5 \mathrm{~b}$ and 5 c, WMRG and R1 waves are consistently stronger in areas of westerly winds. This indicates the ubiquitous impact of the zonal winds in the lower stratosphere on the vertical propagation of equatorial waves.
It is interesting to see that Kelvin wave amplitudes peak just below the zero wind lines of the descending westerly phase and then decrease sharply. This is consistent with the QBO theory that Kelvin waves act to bring the westerly region downward. Similar features also appeared in the analysis of Sounding of the Atmosphere using Broadband Emission Radiometry (SABER) data by Ern et al. (2008) and High-Resolution Dynamics Limb Sounder (HIRDL) data by Alexander and Ortland (2010).

The corresponding evidence for WMRG and R1 waves peaking just below the descending easterly phase is less clear, perhaps because the contribution of the two waves to the downward propagation of the easterly region is relatively small. This may explain the observed feature seen in Fig. 2a that westerly shear zones show more regular and rapid downward propagation than easterly shear zones. However, there is an interesting feature that during some periods of "stalling" in the descent of the easterlies near $30 \mathrm{hPa}$, such as in 1986/87 and 1988/89, WMRG and R1 waves below $30 \mathrm{hPa}$ are less active than in years when there is no such stalling. This suggests that WMRG and R1 waves are playing some role in driving the descent of the QBO easterly winds.

To help quantify the relationship of the QBO winds and wave amplitudes, correlations have been calculated between equatorial $U$ in the lower stratosphere and wave amplitudes in different lower stratospheric layers (Kelvin wave at 20-30 hPa, WMRG at 30-50 hPa, and $\mathrm{R} 1$ at 50-70 hPa). For Kelvin waves the correlations are -0.96 in summer and -0.89 in winter, and for WMRG waves, they are +0.92 in summer and +0.94 in winter. For R1 waves, the correlations are slightly weaker but still large: +0.85 in summer and +0.86 in winter.

\section{c. Zonal variation of wave amplitude}

YHS and YHS07a,b,c showed that wave activity exhibited different characteristics in the Eastern Hemisphere $(\mathrm{EH})$ and Western Hemisphere (WH), partly due to different background winds in the two hemispheres. To contribute the analysis of the longitudeheight variation of waves and their relationship with the zonal wind, Fig. 6 shows cross sections of equatorial $U$ and standard deviations of wave-related winds averaged in the two QBO phases, and the differences between them. In the upper troposphere the equatorial ambient flow (left panels) is very similar in the easterly and westerly phases, in both cases being very different in the two hemispheres with strong easterly in the EH and westerly in the WH. The two westerly ducts over the eastern Pacific and Atlantic in the upper troposphere are much stronger in winter than in summer. In contrast, 

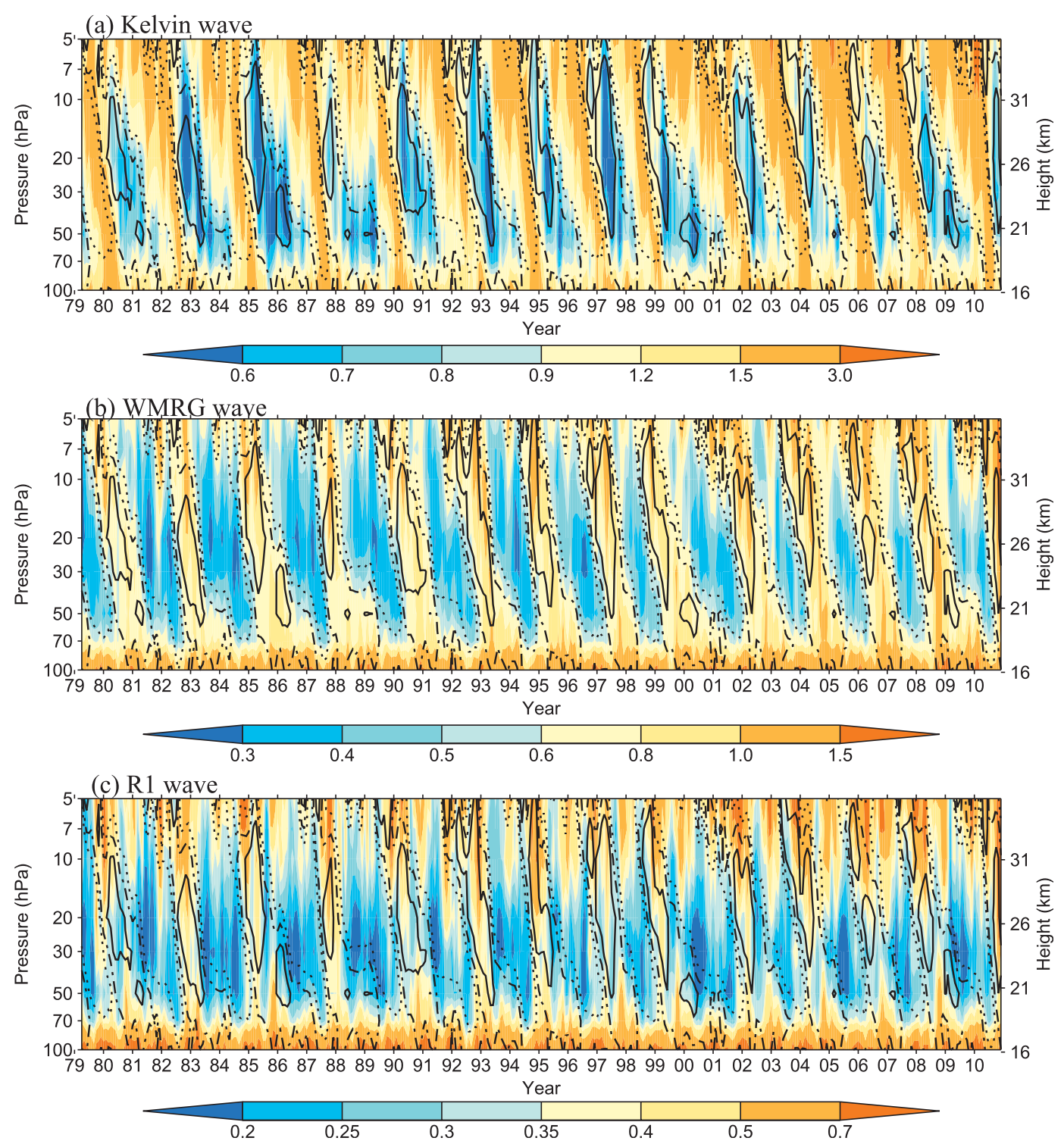

FIG. 5. (a) Time-height cross section of monthly zonal-averaged standard deviations of (a) Kelvin wave equatorial $u$, (b) WMRG wave equatorial $v$, and (c) R1 wave $v$ at $8^{\circ} \mathrm{N} / 8^{\circ} \mathrm{S}\left(\mathrm{m} \mathrm{s}^{-1}\right)$. The black solid and dotted contours indicate monthly mean zonal winds of 10 and $-10 \mathrm{~m} \mathrm{~s}^{-1}$, respectively, and the dot-dashed contour indicates zero wind.

above approximately $100 \mathrm{hPa}$ the zonal winds are clearly very different in the easterly and westerly phases, but there is very little zonal variation. In the easterly phase the lower-stratospheric winds are much weaker in winter than in summer. The next QBO phase, with opposite sign, is evident above about $20 \mathrm{hPa}$.

Consistent with the ambient flows in the lower stratosphere, the amplitude of each of the waves shows very different distributions for the two phases there for both summer and winter. Kelvin wave activity is much stronger in the easterly phase than in the westerly phase. In contrast, WMRG and R1 waves are stronger in the westerly phase. Differences in wave amplitudes in the opposite
QBO phases are further highlighted in Figs. 6c and 6f. This is in agreement with the result of power spectral analysis and consistent with theoretical expectation and the results for the analysis of two summers in YHS11.

It is interesting that there is also longitudinal variation in equatorial wave signatures in the lower stratosphere, particularly in the favorable QBO phases in which upward propagation occurs, although the zonal winds there are quite zonally uniform. This zonal asymmetry appears to reflect asymmetries in the upper troposphere. There the largest variance of the Kelvin wave appears over the warm waters of the $\mathrm{EH}$, and larger amplitudes in the WMRG and R1 waves occur in the WH, especially over 
$U$

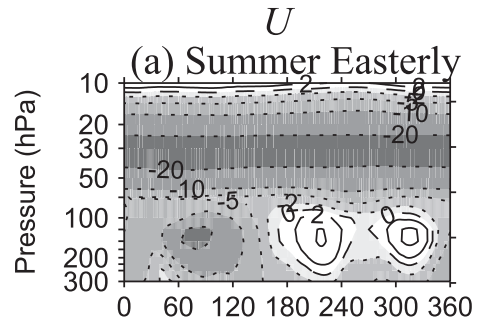

Kelvin

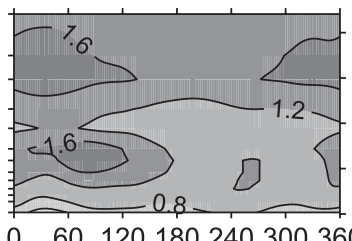

WMRG

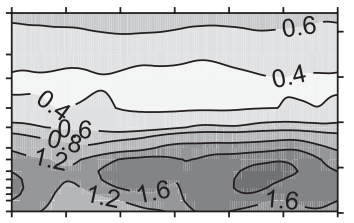

R1
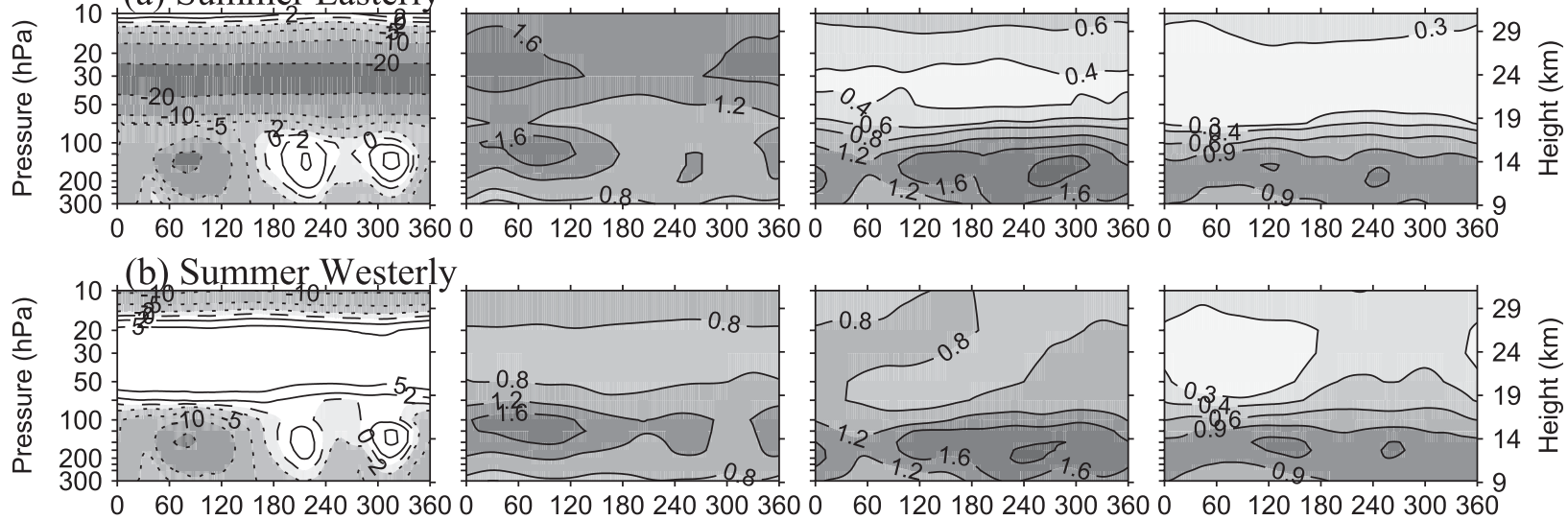

$601201802403003600 \quad 60120180240300360$

(c) Summer E-W
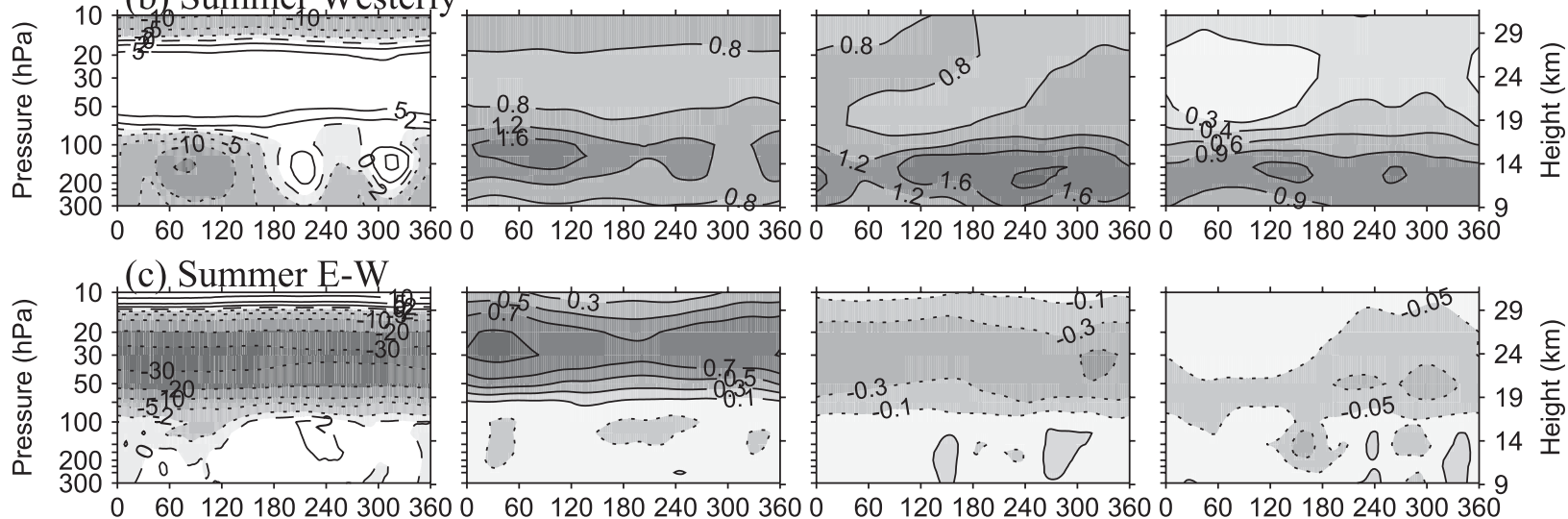

(d) Winter Easterly
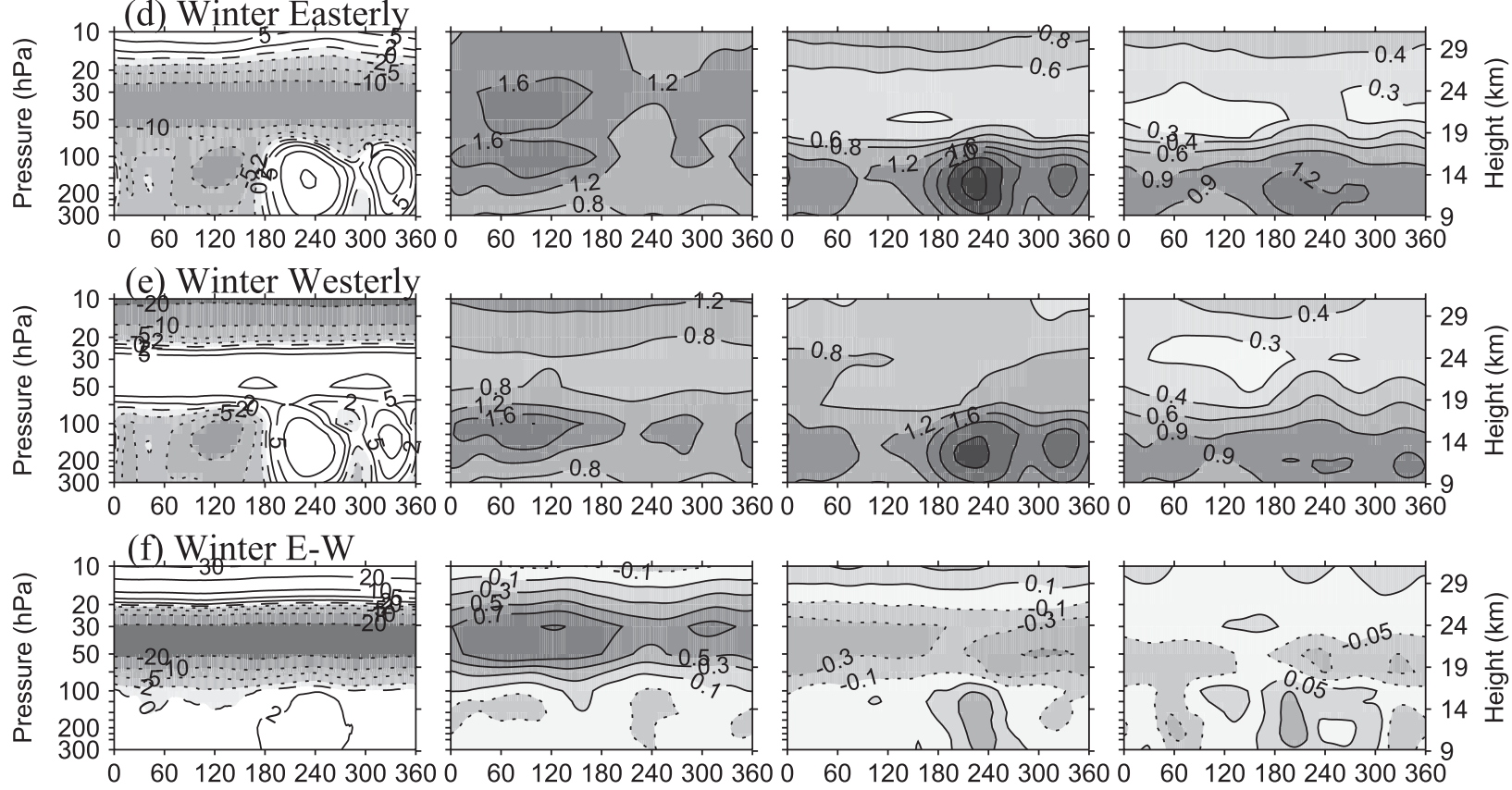

FIG. 6. Longitude-height cross section of (first column) equatorial $\left(5^{\circ} \mathrm{N}-5^{\circ} \mathrm{S}\right) U$, and standard deviations of (second column) Kelvin wave equatorial $u$, (third column) WMRG wave equatorial $v$, and (fourth column) R1 wave $v$ at $8^{\circ} \mathrm{N} / 8^{\circ} \mathrm{S}$, averaged for (a) 6 easterly summers and (b) 10 westerly summers, and (c) the difference between the two phases. (d)-(f) As in (a)-(c), but for winter. Units are $\mathrm{m} \mathrm{s}{ }^{-1}$.

the two westerly ducts of the eastern Pacific and Atlantic. The preferred occurrence of WMRG waves in the eastern Pacific upper troposphere is consistent with that found by Randel (1992). For the Kelvin wave in the easterly phase, its lower stratospheric maximum is over the upper tropospheric maximum in winter and slightly west of it in summer. For WMRG and R1 waves in the westerly phase, their lower stratospheric maxima are east of the upper tropospheric maxima, consistent with their eastward group velocity there as seen in Fig. 3f.

Therefore there is evidence that equatorial wave activity in the lower stratosphere depends not only on the 
QBO winds there but also on the source strength and background zonal winds in the upper troposphere. This dependence on the background winds is consistent with the fact that the EH upper-tropospheric easterly flow is favorable for the upward propagation of the Kelvin waves whereas the $\mathrm{WH}$ westerly flow is favorable for the upward propagation of WMRG and R1 waves.

Another interesting point is that the upper-tropospheric WMRG and R1 waves over the eastern Pacific westerly duct are stronger in the easterly phase than in the westerly phase, particularly in winter. It is found that the amplitudes of the R1 waves in all seven easterly winters consistently show positive anomalies over the region, with four of them having the largest amplitude there, but the opposite does not occur for westerly winters. For WMRG waves, six out of seven easterly winters also have positive anomalies there. However, the impact of the QBO phase is less clear as the ENSO phase also appears to influence the wave. The WMRG and R1 waves in most easterly summers also show positive anomalies, but they are weaker than for the winter case. Analysis suggests that this is because in summer there is a closer relationship between the intensity of the westerly duct and wave amplitudes in the region and the westerly duct intensity is strongly influenced by the phase of ENSO.

However, the difference in WMRG and R1 wave amplitudes in the upper troposphere in opposite QBO phases cannot be fully explained by ENSO variability alone, especially in winter. Excluding all the ENSOinfluenced winters, $\mathrm{QBO}$ winds in the lower stratosphere correlated with the WMRG and R1 wave amplitudes over the upper troposphere in the eastern Pacific region indicate a significant relationship. Then a question is: how in winter can the WMRG and R1 waves in the upper troposphere be related to the QBO phase in the lower stratosphere? A possible answer is that the easterly winds in the lower stratosphere are not favorable for the R1 and WMRG waves to propagate upward; therefore, the waves accumulate in the upper troposphere and compared to other years become larger in amplitude there before dissipation. For the Kelvin wave, the opposite seems to be true with its amplitude in the upper troposphere over the eastern Pacific being weaker in easterly winters than in westerly winters, as seen in Fig. 6. However, the difference is much weaker than that for the WMRG and R1 waves. This may be due to the fact that the zonal winds in the westerly phase are much weaker than in the easterly phase and the Kelvin wave itself has the fastest phase speed, so its upward propagation is less hindered by the unfavorable winds.

\section{d. Vertical variation of amplitude of individual waves}

To examine in each year how the amplitudes of the various waves change with height in the lower stratosphere,
Fig. 7a gives vertical profiles of the zonal mean standard deviations of their characteristic velocity, together with the equatorial $U$, in each easterly and westerly summer. For westward-moving waves, the strongest wind magnitudes consistently occur near the tropopause. Kelvin wave winds also peak at the tropopause but in the easterly phase their strongest peak appears in the lower stratosphere. In all years and for all waves the wind magnitudes decrease sharply above tropopause between 100 and $70 \mathrm{hPa}$. The decrease is most rapid for the R1 waves, for which the magnitude at $70 \mathrm{hPa}$ is about half that at $100 \mathrm{hPa}$.

Consistent differences between easterly and westerly phases become apparent above $70 \mathrm{hPa}$, in agreement with the composites in Fig. 6. Compared with the power spectral profiles in Fig. 4, the differences in wave amplitudes in different phases are further enhanced due to the data being projected onto the different wave modes. There is again very close consistency between the wave wind magnitudes and the ambient zonal flow profiles. For WMRG waves, the difference between the two phases begins at levels very close to where the reversal in the ambient flow occurs. However, for the Kelvin wave there is a slight vertical lag between the two, consistent with its larger upward group velocity (shown in YHS11, and in our Fig. 11 below). The picture for the R1 wave is less clear: for it the difference between the QBO phases occurs only in a shallower layer, consistent with its upward group velocity being the smallest (as will be seen below in Fig. 11). Plots with pressure up to $1 \mathrm{hPa}$ also indicate another vertical reversal for WMRG waves but not for Kelvin waves, consistent with the power spectral profiles in Fig. 4.

To indicate the contribution to kinetic energy, the impact of decreasing density with height is included by multiplying the magnitudes of the winds associated with the waves by $\rho^{1 / 2} \sim \exp (-z / 2 H)$. The results are shown in Fig. 7b. All three waves now show amplitudes that generally decrease with height, particularly in the unfavorable years. However, the amplitude of the Kelvin wave in the easterly phase shows no reduction with height in the region $30-70 \mathrm{hPa}$ but with a slight increase, consistent with it experiencing least dissipation when propagating upward into the lower stratosphere, because of its large vertical group velocity (see Fig. 11 and Table 1 below).

Weighted wave velocity pictures for the winter case in Fig. 7c show similar features to those in summer but as above the difference between the QBO phases occurs in shallower layer.

The increase of Kelvin wave kinetic energy can be explained by the fact that conservative waves conserve their EP flux $E$, so that the wave action density $E / \omega_{i}$ increases as $\omega_{i}=k[c-U(z)]$ decreases. Therefore, some 

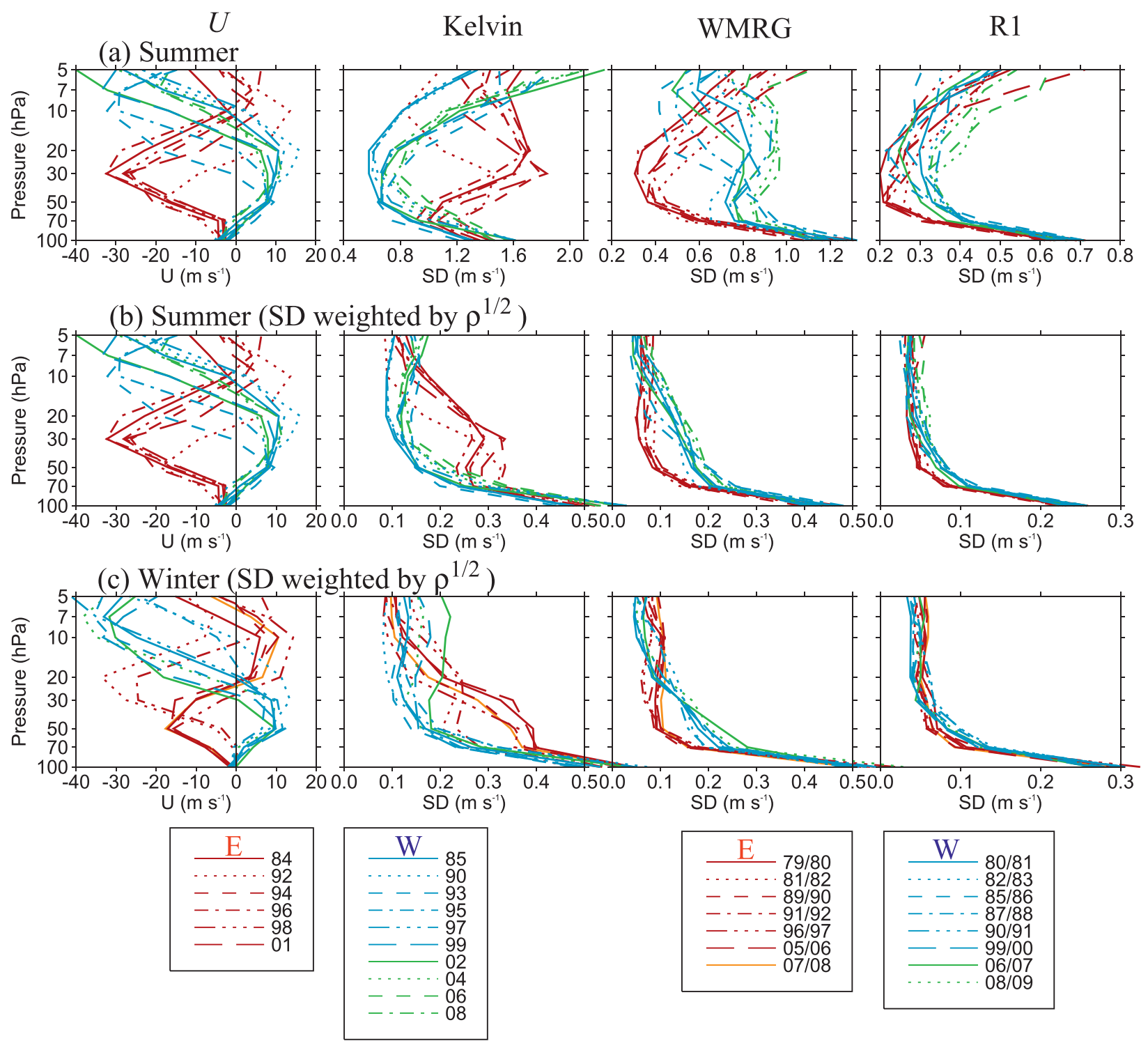

FIG. 7. (a) Vertical profile of equatorial $U$ and of the standard deviations (SD) of waves in each easterly (red or orange) and westerly (blue or green) summer. (b) As in (a), but with SD weighted by the square root of the density $\left[\rho^{1 / 2} \sim \exp (-z / 2 H)\right.$, where $H$ is the scale height, which is taken to be $7 \mathrm{~km}$ ]. (c) As in (b), but for winter.

increase in wave kinetic energy might be expected approaching the critical level, unless dissipation dominates.

\section{Composite propagation features}

YHS11 analyzed in some detail features of vertical propagation in one easterly and one westerly summer. In the next section, a similar analysis is performed for all 32 years in 1979-2010. As the composites for winter and summer stratified with respect to the QBO phase are generally very similar, the sum of these will be shown here, and since in the lower stratosphere the Kelvin wave activity is stronger in the EH and WMRG and R1 waves are stronger in the $\mathrm{WH}$, some composite analysis will be based on these regions.

\section{a. Period, zonal wavelength, and phase speed}

To obtain typical wave properties and examine how they vary with height, autoregression of equatorial waves is performed at each level as in YHS11. Typical periods, zonal wavenumbers, and amplitudes can be determined. When calculating the autoregression/correlation, extremes exceeding a threshold in a specified field in a longitude-time domain (one hemisphere and 6 months) with data on a grid $2^{\circ} \times 1$ day are selected. There are typically of order 1000 extremes in each of the fields 

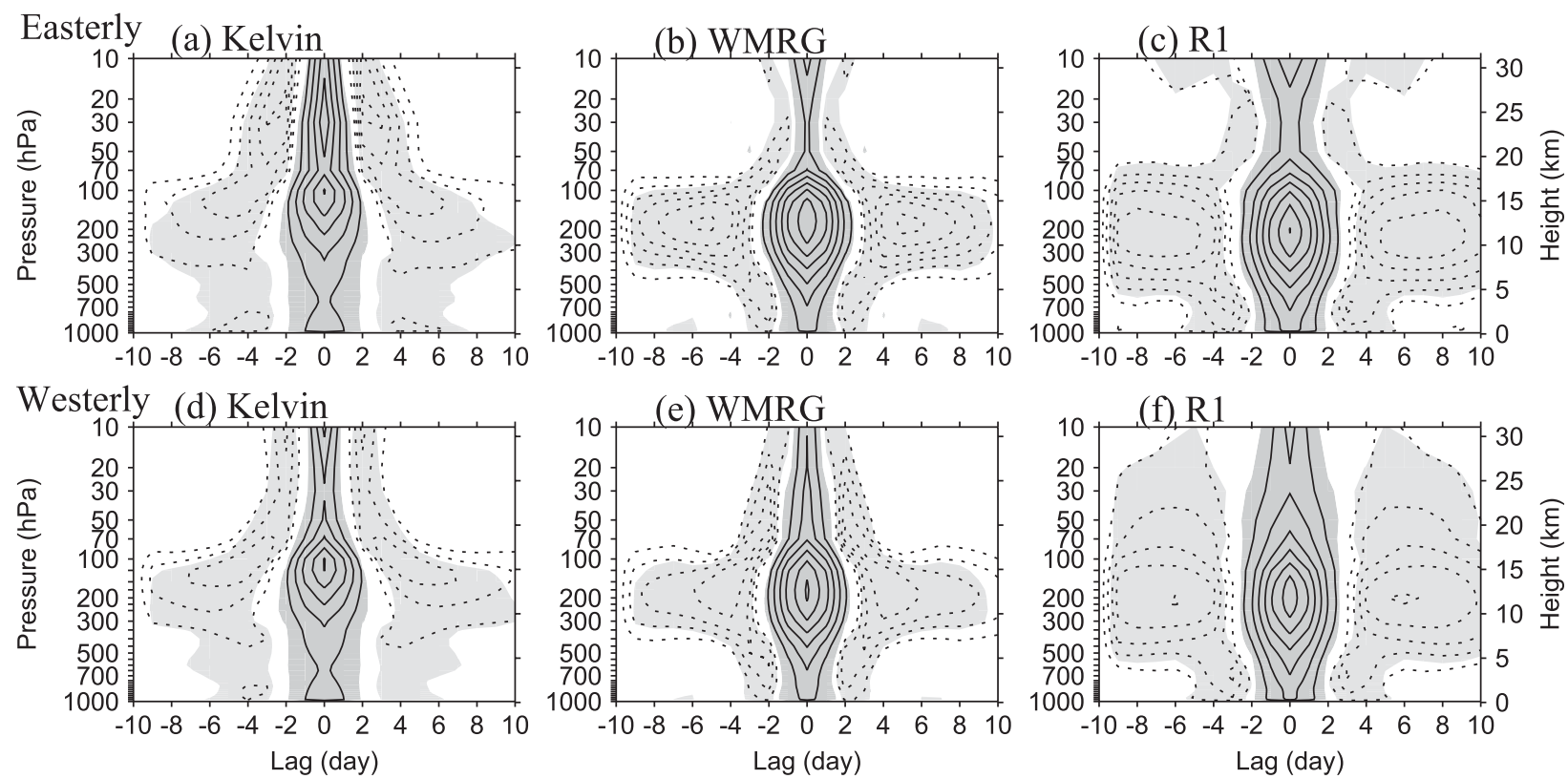

FIG. 8. Autoregression of wave velocities as a function of lag time and height for (a),(d) EH Kelvin wave equatorial $u$, (b),(e) WH WMRG wave equatorial $v$, and (c),(f) WH R1 wave $v$ at $8^{\circ} \mathrm{N} / 8^{\circ} \mathrm{S}$, averaged for all easterly and westerly summers and winters. The solid (dashed) lines are for positive (negative) values. The contour intervals are $0.6 \mathrm{~m} \mathrm{~s}^{-1}$ for positive values and $0.2 \mathrm{~m} \mathrm{~s}^{-1}$ for negative values with the zero contours suppressed, except in (c) and (f), where the contour interval is halved. The regression value is taken to be 1.5 times the standard deviation peak of the winds. The shaded area denotes regressions exceeding the $95 \%$ significance level.

considered here. However, investigation suggests that the number of degrees of freedom should be taken as onetenth of this sample number, and this assumption is used in calculating the statistical significance of the linear relationships found using a $t$ test.

Figure 8 shows the results of autoregression, as a function of lag time, averaged separately for easterly and westerly QBO seasons. Note that here the troposphere is shown as well as the stratosphere. A typical period can be deduced from the two neighboring negative extrema to the left and right of the central day. Several interesting points emerge.

First, for waves in the unfavorable phase (the Kelvin wave in the westerly phase and WMRG and R1 waves in the easterly phase), regressed amplitudes decrease sharply above about $70 \mathrm{hPa}$, indicating strong wind filtering of the waves.

Second, wave periods are generally much shorter in the lower stratosphere than in the upper troposphere. The decrease of wave period with height was also noted by Dunkerton (1993) using cross-spectra. In the troposphere the dominant period for Kelvin waves is about 10 days (individual years in the range of 8-12 days). In the lower stratosphere their dominant period is reduced to 6 days in the easterly phase and 4 days for the westerly phase. WMRG waves in the upper troposphere have a dominant period of 10 days ( 8 days in summer and 12 days in winter). Their dominant period decreases sharply in the lower stratosphere to the 3-4 days in the easterly phase and 4-5 days in the westerly phase. R1 waves in westerly years have a period of 12-14 days (summer has a rather shorter period) and through to the lower stratosphere $(10 \mathrm{hPa}$ for westerly summer and $30 \mathrm{hPa}$ in westerly winter). This is consistent with the quite barotropic structure found in the $\mathrm{WH}$ in YHS07c. In the easterly phase, the dominant period of $\mathrm{R} 1$ waves can reach $70 \mathrm{hPa}$ and then decreases sharply to 6 days in the region in which its coherence is also much reduced.

Third, the period in the lower troposphere of both WMRG and R1 waves is also shorter than that in the upper troposphere, in agreement with the finding of YHS11 that as WMRG and R1 waves propagate downward as well as upward away from their upper-tropospheric source region, their period decreases.

Autoregressions as a function of longitude and height are shown in Fig. 9. Here, a typical zonal wavelength can be deduced from the two longitudes corresponding to the two neighboring negative extremes.

Zonal wavelengths increase with height so that the zonal wavenumber $k$ is smaller in the lower stratosphere than in the upper troposphere. For the Kelvin wave, the typical $k$ is 6 in the upper troposphere and 3 in the lower stratosphere. There is also an indication of a secondary wavenumber 3 in the upper troposphere. The WMRG 

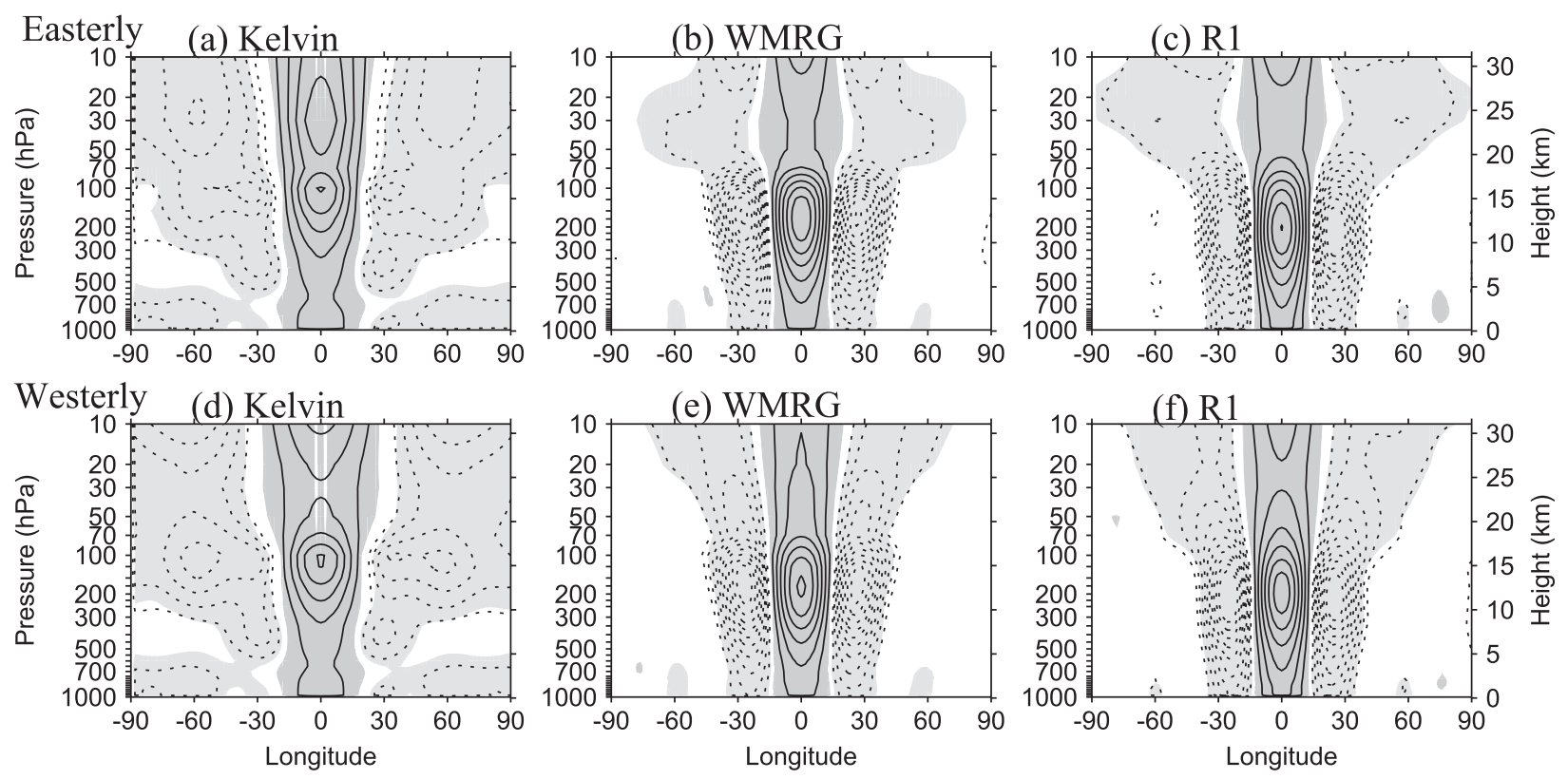

FIG. 9. As in Fig. 8, but for autoregression of wave velocities as a function of longitude and height.

and R1 waves have a typical $k$ of 7 in the troposphere. In the westerly phase, between 70 and $50 \mathrm{hPa}$, the typical $k$ is 6 for WMRG waves and 5-6 for R1 waves, and reduces to $4-5$ beyond $50 \mathrm{hPa}$ (Figs. 9e,f). In the easterly phase, the typical $k$ is $4-5$ between $70-50 \mathrm{hPa}$, with a weak signal of $k=3-4$ beyond $50 \mathrm{hPa}$ (Figs. 9b,c), indicating that only waves with longer wavelength can propagate upward in the unfavorable phase. The dominant zonal wavenumber for all waves in the troposphere is $6-7$, as was the case for convectively coupled waves there (YHS07a,b,c).

The generally shorter periods and longer zonal wavelengths in the lower stratosphere shown in Figs. 8 and 9 imply that the phase speeds of the waves are larger there than in the upper troposphere. This suggests that there is either enhanced dissipation or filtering of the slow waves. In addition, between 20 and $70 \mathrm{hPa}$ all of the waves have shorter periods and longer wavelengths in their unfavorable years than in their favorable years. This implies that the waves that are present in the unfavorable QBO phase have larger phase speeds than those in the favorable phase: it is the faster waves that propagate into the lower stratosphere, especially in an unfavorable year. This is suggestive of a mixture of filtering and Doppler shifting, consistent with theory and with the results shown in YHS11.

To avoid excessive numerical detail in the text and to help in the consolidation of the results, the period and zonal wavenumbers, together with other propagation parameters, as will be discussed below, are summarized in Table 1 . Note that this table shows propagation parameters only in the lower stratosphere but separately for summer and winter.

A quantitative estimate of the zonal phase speeds of the waves can be obtained using the Radon transform (RT) method (Radon 1917), as in YHS07b, Yang et al. (2009), and YHS11, with details given in the former. The vertical profiles of the derived zonal mean phase speeds for the Kelvin, WMRG, and R1 waves for each easterly and westerly in summer and winter are shown in Figs. 10a and 10b. The phase speeds for all waves in the stratosphere are seen to be generally larger than those in the troposphere, as discussed above. Also, in the different QBO phases the phase speeds are very similar in the troposphere but quite different in the stratosphere. In the lower stratosphere, the phase speed of the Kelvin wave is smaller in the easterly phase than in westerly phase, and the situation is reversed for the westward-moving WMRG and R1 waves, again consistent with the previous discussion. Comparing with the corresponding zonal wind profile (left column of Fig. 7; note that the pressure levels start from $100 \mathrm{hPa}$ there), and noting that the phase speeds have opposite tendencies where the zonal wind differences reverse, it is clear that the phase speed differences are consistent with a measure of Doppler shifting by the ambient zonal flows. However, the magnitude of the difference in phase speeds seems not to be as large as the difference in the zonal winds, as also can be seen in Table 1, where only the WMRG wave shows a similar magnitude.

The WMRG wave in the easterly summer in 1984 is seen to have a very large phase speed of about 
TABLE 1. Zonal wavenumber $k$, zonal phase speed $c$, period $p$, vertical phase speed $c_{z}$, vertical wavelength $D$, and vertical group velocity $c_{g z}$ for EH Kelvin wave and WH WMRG and R1 waves in the lower stratosphere in the easterly and westerly summers and winters. The lower stratosphere is for the region where a wave is prevalent, which is about 30-100 hPa for the Kelvin wave and 50-100 hPa for the WMRG and R1 waves. Values of $D$ and $c_{g z}$ in parentheses indicate their theoretical values from Eqs. (8)-(13), and $c<0$ and $c_{z}<0$ indicate westward phase speed and downward phase speed, respectively.

\begin{tabular}{|c|c|c|c|c|c|c|c|c|c|}
\hline Wave & Season & Phase & $U\left(\mathrm{~m} \mathrm{~s}^{-1}\right)$ & $k$ & $c\left(\mathrm{~m} \mathrm{~s}^{-1}\right)$ & $p$ (day) & $c_{z}\left(\mathrm{~km} \mathrm{day}^{-1}\right)$ & $D(\mathrm{~km})$ & $c_{g z}\left(\mathrm{~km} \mathrm{day}^{-1}\right)$ \\
\hline \multirow[t]{4}{*}{ Kelvin } & Summer & $\mathrm{E}$ & -14 & 3 & 19 & 6 & -1.4 & $8.0(9.4)$ & $2.4(2.0)$ \\
\hline & & W & 3 & 3 & 28 & 4 & -0.9 & $6.0(6.8)$ & $1.1(1.1)$ \\
\hline & Winter & $\mathrm{E}$ & -10 & 3 & 20 & $5-6$ & -1.2 & $8.0(8.6)$ & $1.8(1.7)$ \\
\hline & & $\mathrm{W}$ & 3 & 3 & 29 & 4 & -0.9 & $6.0(7.4)$ & $1.4(1.2)$ \\
\hline \multirow{4}{*}{ WMRG } & Summer & $\mathrm{E}$ & -7 & $4-5$ & -26 & 3 & -1.3 & $5.0(3.6)$ & $0.5(0.2)$ \\
\hline & & $\mathrm{W}$ & 2 & 6 & -17 & 4 & -1.4 & $8.0(13.4)$ & $1.2(0.7)$ \\
\hline & Winter & $\mathrm{E}$ & -4 & $4-5$ & -24 & 4 & -1.0 & $5.0(4.2)$ & $0.9(0.3)$ \\
\hline & & $\mathrm{W}$ & 6 & 6 & -14 & 5 & -1.4 & $8.0(17.4)$ & $1.2(0.9)$ \\
\hline \multirow[t]{4}{*}{$\mathrm{R} 1$} & Summer & $\mathrm{E}$ & -7 & $4-5$ & -14 & 6 & -1.4 & $10.0(6.6)$ & $0.5(0.4)$ \\
\hline & & W & 2 & $5-6$ & -10 & 12 & -2.1 & $18.0(16.0)$ & $0.6(1.4)$ \\
\hline & Winter & $\mathrm{E}$ & -4 & 5 & -13 & 6 & -1.3 & $10.0(9.8)$ & $0.5(0.7)$ \\
\hline & & W & 6 & $5-6$ & -9 & 12 & -2.3 & $20.0(22.8)$ & $1.1(2.1)$ \\
\hline
\end{tabular}

$-80 \mathrm{~m} \mathrm{~s}^{-1}$ at $30 \mathrm{hPa}$. Referring to Fig. 7a, the ambient flow at $30 \mathrm{hPa}$ in this summer is very strong easterly at about $-33 \mathrm{~m} \mathrm{~s}^{-1}$. The phase speed for this summer is consistent with the wave having a very short period of 2 days and small $k$ of 3 .

To examine the dependence of the phase speed on the hemispheres, Fig. 10c shows the phase speed in the EH (thick line) and WH (thin line) averaged in easterly (red) and westerly (blue) summer. Note that the corresponding equatorial $U$ is also shown. It is interesting to see that in the lower stratosphere, the difference in the phase speed between the two hemispheres is just apparent, especially in their favorable QBO phase. In their favorable phase, the lower-stratospheric phase speeds in the unfavorable hemispheres-that is, the Kelvin wave in the WH (thin red line) and WMRG and R1 waves in the EH (thick blue line)-are faster than in the other hemisphere (thick red and thin blue lines, respectively). One may argue that the difference may be a continuation of that in the upper troposphere presumably due to Doppler shifting. However, the difference in the lower stratosphere is larger than that at $150 \mathrm{hPa}$ where the zonal winds have the largest difference hence the largest Doppler shifting. This indicates that the upper-tropospheric ambient flows also act as a filter for slow waves, consistent with that discussed previous.

\section{b. Vertical propagation parameters}

To obtain a composite view of the vertical structure and vertical propagation of the waves and the dependence on the QBO phase, their characteristic wind component at all levels has been regressed onto extremes of the same wind component at $100 \mathrm{hPa}$ as a function of time lags and composited for all longitudes in each hemisphere. Figure 11 shows results for the EH Kelvin waves and WH
WMRG and R1 waves for the two QBO phases averaged for summer and winter. Typical vertical phase speed, vertical wavelengths, and vertical group velocities can be estimated from this diagram. Table 1 gives these parameters but with summer and winter separately. It should be pointed out that in the $100-20-\mathrm{hPa}$ region, the vertical resolution of the data is about $2-3 \mathrm{~km}$, hence some waves with small vertical wavelengths may be not accurately represented by the data and this may also affect the choice of optimum $y_{0}$; however, as will be shown below, the analysis is not sensitive to $y_{0}$.

It is seen that in the upper troposphere and the lower stratosphere, all waves clearly show upward group velocity but downward phase speed, consistent with theory [Eqs. (8)-(13) and Table 1]. As expected, in the unfavorable phases (Figs. 11d,b,c), upward propagation is less clear and the lower-stratospheric waves have smaller vertical group velocities and vertical wavelengths than those in the favorable phase (Figs. 11a,e,f), again consistent with theory. Kelvin waves in the easterly phase have an upward group velocity $c_{g z}$ of $2.2 \mathrm{~km} \mathrm{day}^{-1}$, a downward phase speed $c_{z}$ of $1.2 \mathrm{~km} \mathrm{day}^{-1}$, and a vertical wavelength of $8 \mathrm{~km}$. WMRG waves in the westerly phase have an upward group velocity of $1.2 \mathrm{~km} \mathrm{day}^{-1}$, a downward phase speed of $1.4 \mathrm{~km} \mathrm{day}^{-1}$, and vertical wavelength of $8 \mathrm{~km}$. The $\mathrm{R} 1$ wave in the troposphere is dominated by the barotropic structure and smaller tilt in the stratosphere. In the westerly phase the R1 wave has an upward group velocity of $0.8 \mathrm{~km} \mathrm{day}^{-1}$ and a larger downward phase speed of $2.3 \mathrm{~km} \mathrm{day}^{-1}$, consistent with its longer vertical wavelength of about $20 \mathrm{~km}$. It is of interest that in the westerly phase, the WMRG wave signal disappears at a lower level in the lower stratosphere than the R1 wave, although the latter, which has slower phase speed, is expected to meet a critical line 

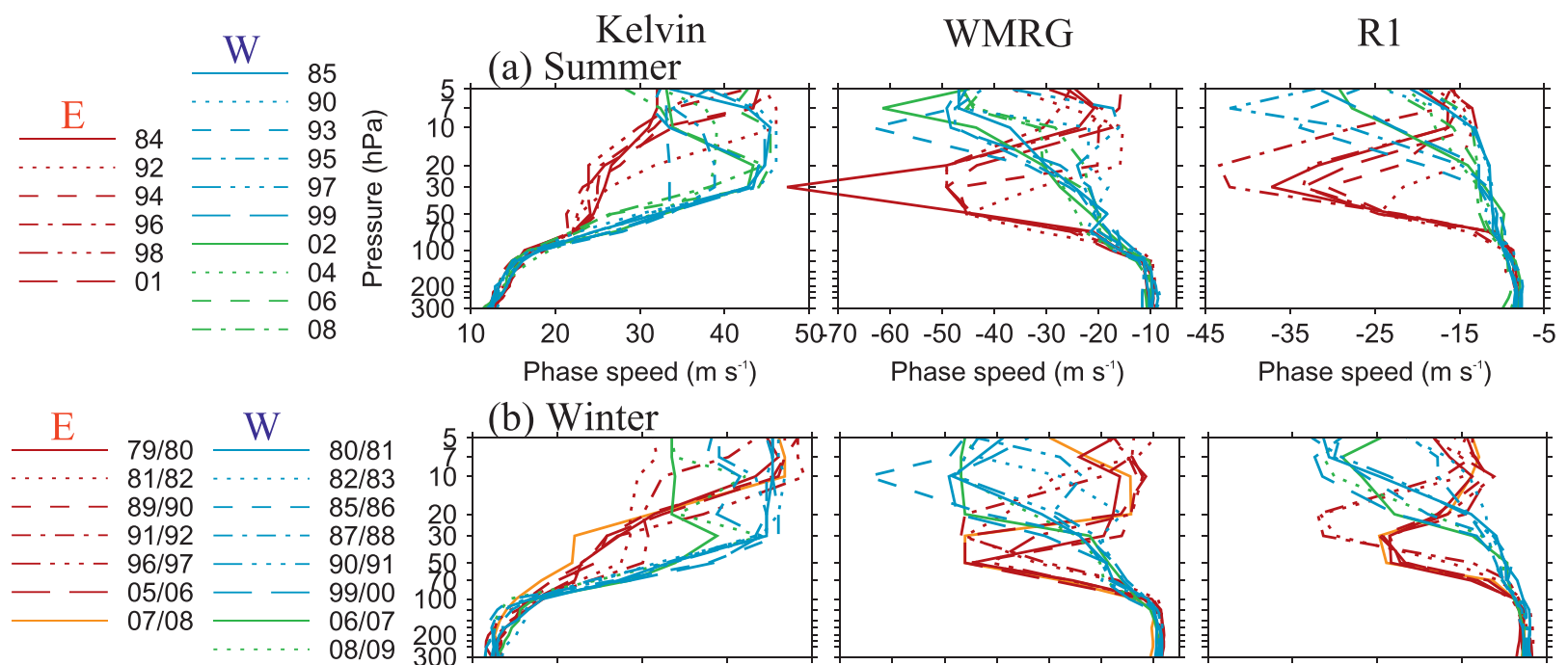

(b) Winter
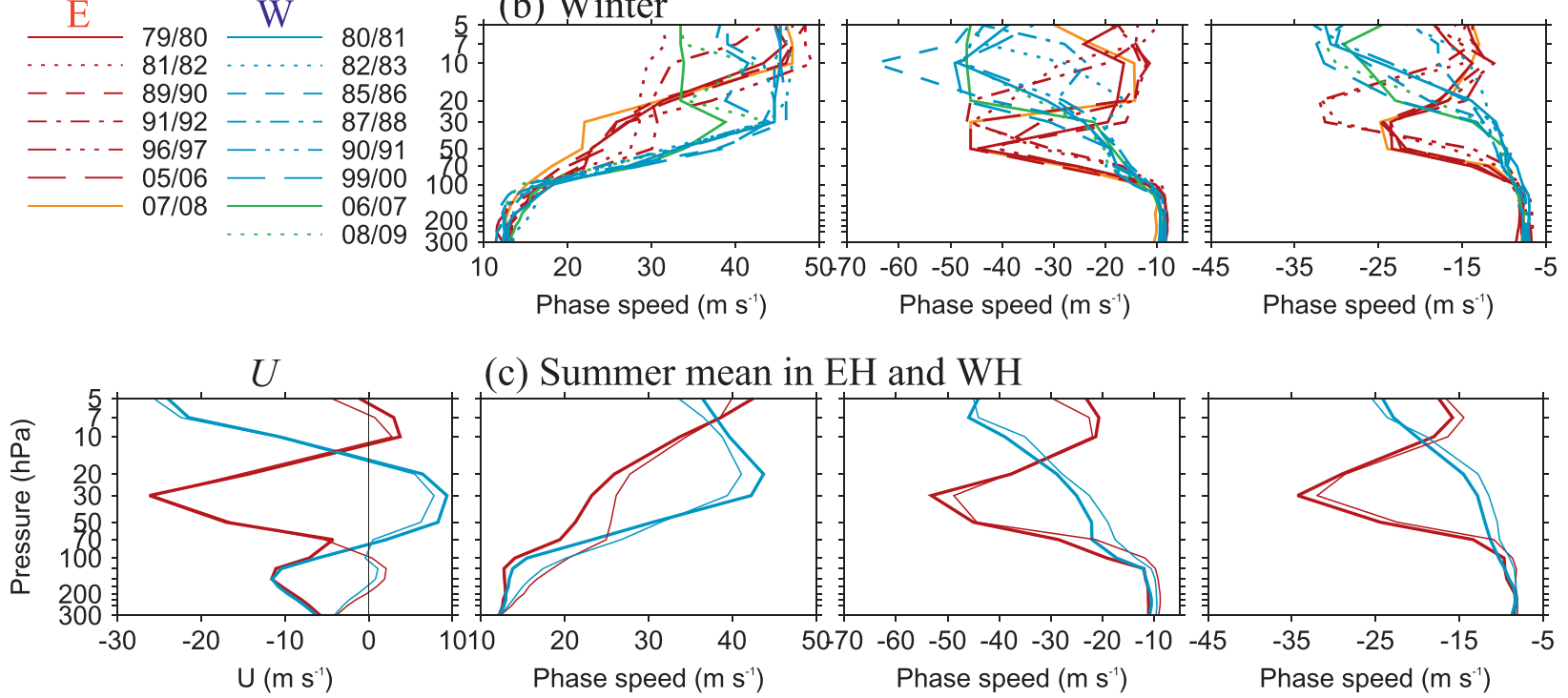

FIG. 10. Wave phase speeds for each of the easterly (red or orange) and westerly (blue or green) seasons in the upper troposphere and lower stratosphere for (a) summer and (b) winter. (c) Equatorial $U$ and phase speeds, averaged for all easterly (red) and westerly (blue) summer, for the EH (thick solid) and WH (thin solid).

at a lower level. This is consistent with theory [Eqs. (12) and (13) in YHS11] that the WMRG wave is more susceptible to dissipation when approaching a critical line.

The WMRG and R1 waves appear to be initiated in the upper troposphere near $150 \mathrm{hPa}$, and to then propagate both upward and downward from there. Their downward group velocities are about 1.9 and 1.2 $\mathrm{km}$ day $^{-1}$, respectively, somewhat larger than their upward group velocities in the upper troposphere and lower stratosphere. The two-way propagation of the WMRG wave out of the upper tropospheric region was also observed by Dunkerton and Baldwin (1995), who used an objective rotated EOF method. The initiation of the R1 and WMRG waves in the upper troposphere is consistent with the middle latitude forcing of the waves (YHS07c) and their variability in the two westerly ducts shown in Fig. 6.

The zonal and vertical propagation parameters obtained in the composite analysis are quantitatively comparable to those obtained for the two summers in YHS11 using poorer vertical resolution ERA-40 data. The vertical wavelength and vertical group velocity are compared with those predicted by theory using Eqs. (8)-(13) indicated by values in the parentheses in Table 1. It shows that they are in general agreement with theoretical values, except for vertical wavelengths of WMRG waves. In this case, the large discrepancy is consistent with Eq. (9) and the implied sensitivity of $m^{-1}$ as $\beta / k^{2}+$ $c-U(z)$ becomes small (see Fig. 2 of YHS11).

\section{c. The sensitivity of analysis to the $y_{0}$}

To test the sensitivity of the analysis technique to the choice of the trapping scale, as $6^{\circ}$, the analysis has been performed using a range of alternate values of $y_{0}=5,7$, and $8^{\circ}$ for the ERA-40 24-yr data for 1979-2002. In this period there are six easterly and six westerly summers, and five easterly and six westerly winters, as for ERAInterim in this period. Confirming the result found in YHS, the longitude-height structures of equatorial waves are found to be insensitive to the choice of $y_{0}$. Zonal phase speeds and standard deviations of waves averaged in the easterly and westerly summers are 

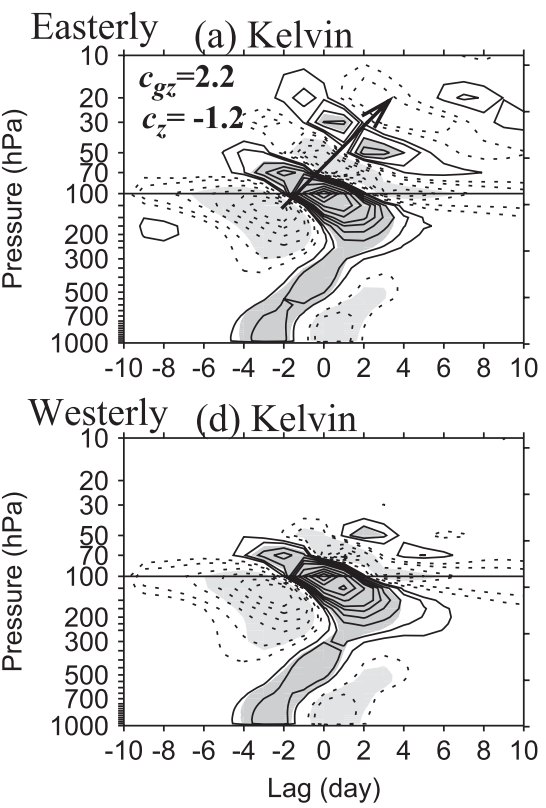
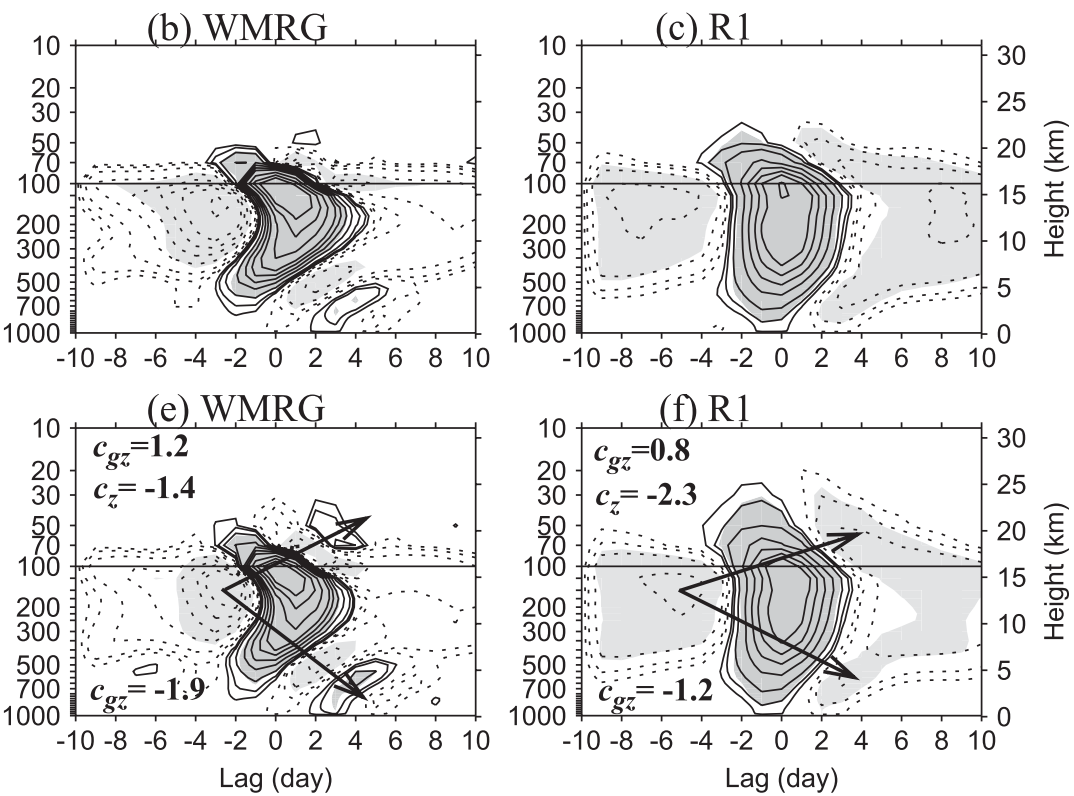

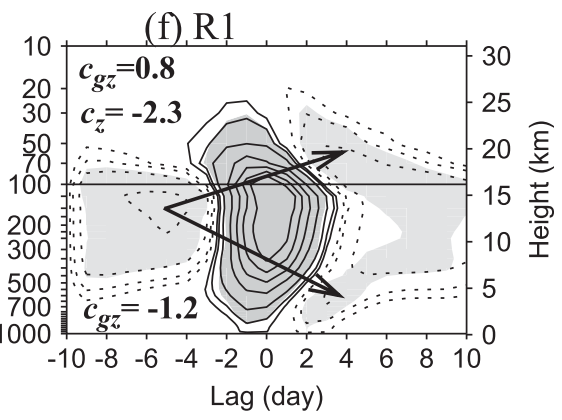

FIG. 11. Winds in waves at each level regressed onto their 100-hPa extremes, as a function of time for (a)-(c) easterly and (d)-(f) westerly QBO years. (a),(d) EH Kelvin wave equatorial $u$; (b),(e) WH MRG wave equatorial $v$, (c),(f) WH R1 wave $v$ at $8^{\circ} \mathrm{N} / 8^{\circ} \mathrm{S}$. Arrows in favorable phases indicate the direction of wave propagation and $c_{g z}$ and $c_{z}$ indicate vertical group velocity and vertical phase speed $\left(\mathrm{km} \mathrm{day}^{-1}\right)$. Solid (dashed) contours denote positive (negative) winds. Contour values are $\pm 0.1,0.2,0.4,0.6,0.8,1.0,1.4,1.8,2.2$, and $2.6 \mathrm{~m} \mathrm{~s}^{-1}$. The shaded area denotes regressions exceeding the $95 \%$ significance level.

shown in Fig. 12. It is even found that the zonal phase speeds are completely insensitive to the choice of $y_{0}$. This contrasts strongly with the theoretical relationship between $y_{0}$ and $c_{e}$ that underlies analyses based on equivalent depths. As shown in Fig. 12b the meridional wind amplitudes of WMRG and R1 change only slightly with the trapping scale. However, the zonal wind amplitude of the Kelvin wave is more sensitive to $y_{0}$. This is perhaps consistent with the projection of $q=\alpha Z+u$ for the Kelvin wave and the strong theoretical dependence of $\alpha$ on $y_{0}$ (i.e., $y_{0}^{-2}$ ). Nevertheless, all the conclusions for the differences between the opposite QBO phases, including vertical propagation parameters, are found to hold for these different values of $y_{0}$.

\section{Relationship with tropical convection}

To investigate possible linkage between equatorial waves in the lower stratosphere and tropical convection, NOAA daily OLR data are first separated into eastwardand westward-moving components. OLR at a particular latitude is then regressed onto extremes in wind fields characteristic of waves. Figure 13 shows the results for wind fields at $50 \mathrm{hPa}$ : the $\mathrm{EH}$ Kelvin wave equatorial $u$ for the eastward component and the WH WMRG equatorial $v$ and $\mathrm{R} 1$ wave off-equatorial $v$ for the westward component. This calculation is performed at a range of time lags/leads and composited for all longitudes in one hemisphere. The choice of the different latitudes for the convection is based on theory and results in YHS 07a and YHS11. The wind maximum is moved to $0^{\circ}$ longitude and day 0 .

It is seen in Fig. 13 that waves in the lower stratosphere in their favorable QBO phase are, to some extent, related to tropical convection. The relationship varies with season and the wave type. The convective signal associated with the Kelvin wave and R1 waves is strongest in winter. The signal associated R1 waves in summer and WMRG waves in both seasons is weak. These convective signals generally have bias to negative lag, indicating that convection tends to appear before the stratospheric waves. This bias is less clear for R1 waves, perhaps associated with their deep vertical structure. Also, the convective signal associated with Kelvin waves has a nondispersive signature whereas those associated with the WMRG and R1 waves exhibit eastward group velocities, consistent with equatorial wave theory and the tropospheric characteristics of convectively coupled waves found in YHS 07a,b and YHS11.

The convective signals have different zonal phase speeds for different waves in different seasons. The Kelvin wave is slower in summer, $16 \mathrm{~m} \mathrm{~s}^{-1}$, than in winter, $22 \mathrm{~m} \mathrm{~s}^{-1}$. The phase speed for $\mathrm{R} 1$ waves in winter is the slowest, $7 \mathrm{~m} \mathrm{~s}^{-1}$. Comparing with Fig. 10, except for 

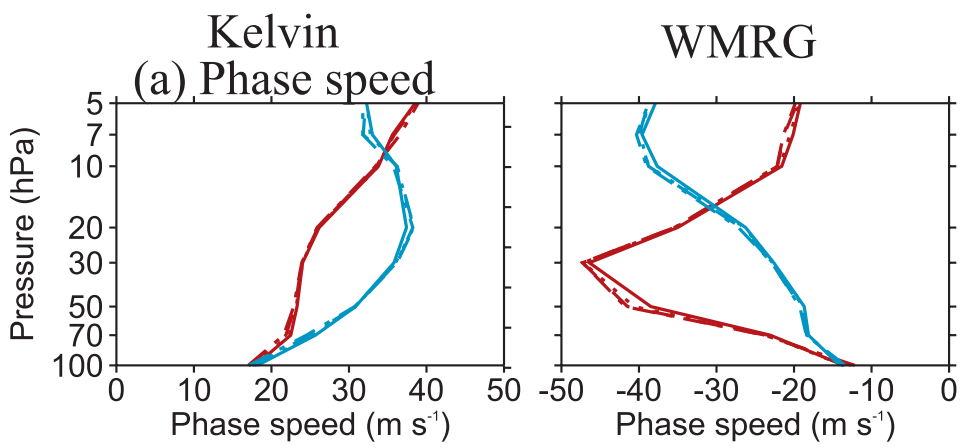

(b) Standard deviation
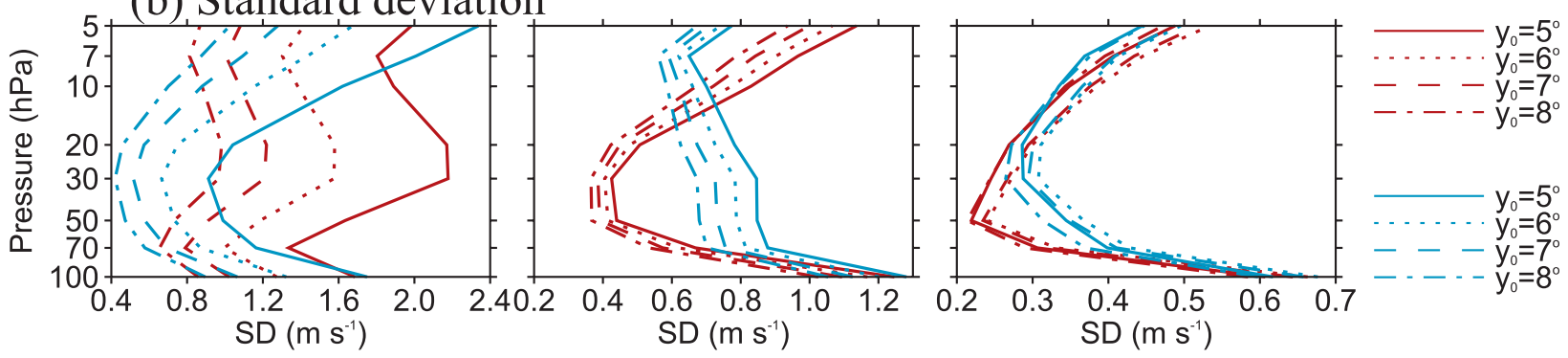

FIG. 12. Vertical profiles of (a) phase speeds and (b) standard deviations of waves averaged in easterly (red) and westerly (blue) summer for the trapping scale $y_{0}=5^{\circ}, 6^{\circ}, 7^{\circ}$, and $8^{\circ}$, for ERA-40 data in 1979-2002.

the Kelvin wave in winter, these phase speeds are slower than the corresponding speed of the typical dynamical waves at $50 \mathrm{hPa}$, about $22 \mathrm{~m} \mathrm{~s}^{-1}$ for the Kelvin wave and $10 \mathrm{~m} \mathrm{~s}^{-1}$ for R1 waves. This suggests that convectively coupled waves, with their slower phase speed, may be more susceptible to dissipation. Nevertheless, they can to some extent propagate into the lower stratosphere when the phase of the QBO in the lower stratosphere is favorable.

A similar analysis for the unfavorable phase shows no significant convective signal associated with lowerstratospheric waves. This lack of significant convective signals is consistent with wave dissipation at a critical level below $50 \mathrm{hPa}$. Analysis also shows a lack of significant convective signals associated waves in the other hemisphere even in the favorable year, except for weak signals for the WH Kelvin waves in the easterly phase. This is suggestive of the importance of upper-tropospheric background winds and tropospheric forcing for the presence of upward-propagating convectively coupled waves, a result consistent with the simulation study of Kawatani et al. $(2009,2010 b)$.

\section{Summary and discussion}

The variations of stratospheric equatorial wave characteristics with the phase of the QBO have been analyzed using ERA-Interim data for the period 1979-2010 for extended boreal summers and winters. Along with the
Kelvin and WMRG waves, the $n=1$ Rossby wave has also been analyzed. The analysis reveals the zonal and vertical behavior of equatorial waves and their zonal and vertical propagation wavelengths, phase speeds, and group velocities, and also their relationship to tropical convection.

A similar analysis has also been performed for the 24 years of ERA-40 data for 1979-2002. The results have been found to be extremely similar to those shown here for ERA-Interim. Taken together with the similarity of the results shown in YHS11 for two summers using ERA40 data; this is indicative of the robustness of the results.

The fact that ambient flows act as a filter for the waves has been clearly demonstrated: upward-propagating Kelvin waves have larger amplitudes in the easterly QBO phase than in the westerly phase, and westward-moving WMRG and R1 waves are larger in the westerly phase. These characteristics are generally consistent with theory, indicating filtering/dissipation dependent on the ambient flow, especially in unfavorable QBO phases. This difference in the wave amplitude exists in a deeper layer in the lower stratosphere in summer than in winter, consistent with the seasonality of the ambient zonal winds.

The R1 wave in the stratosphere has in the past received less attention than the Kelvin and WMRG waves. This study has revealed general features of the propagation of the R1 wave in the lower stratosphere, their source region in the upper troposphere, and their association with $\mathrm{NH}$ off-equatorial convection. 

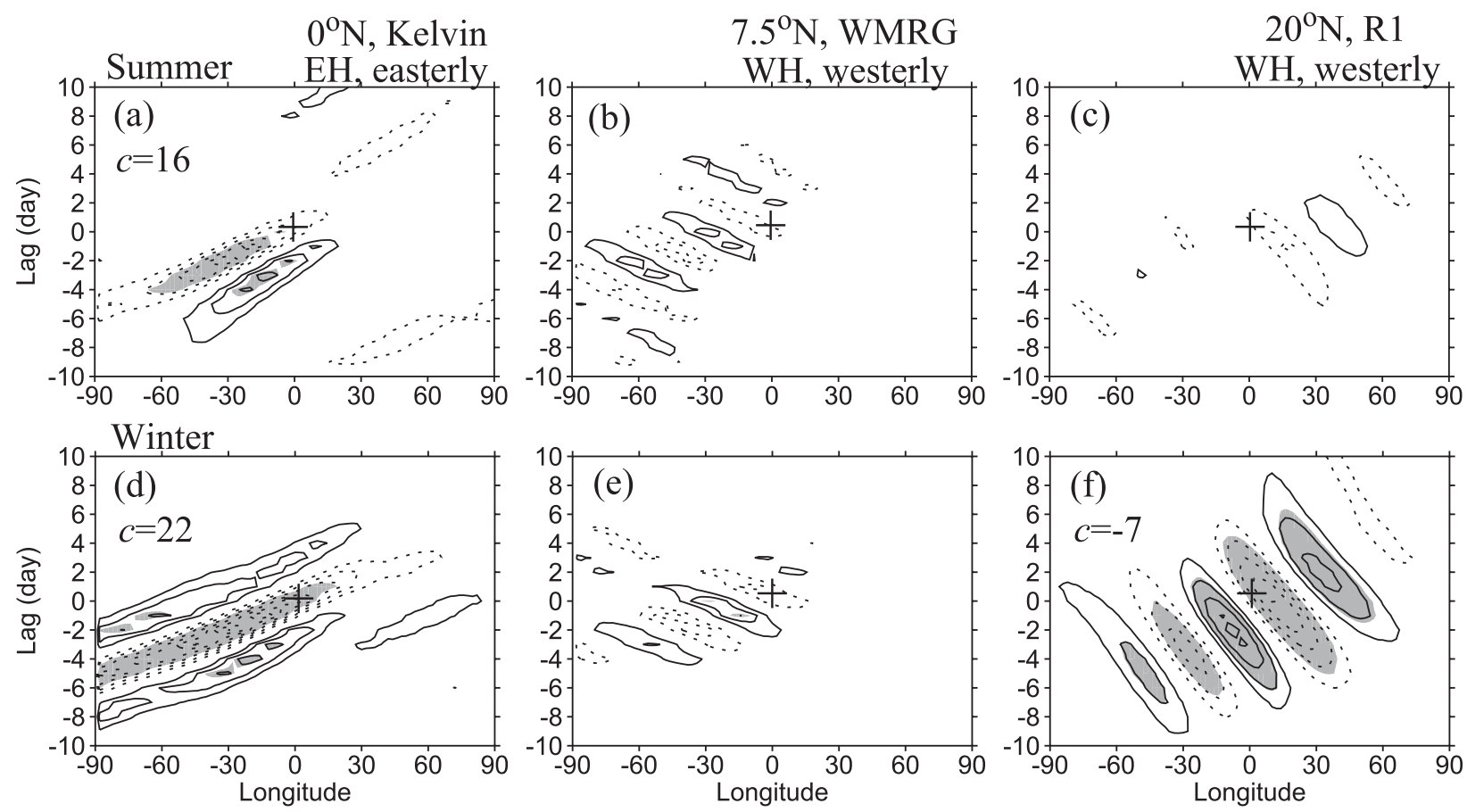

FIG. 13. OLR at different latitudes regressed onto 50-hPa equatorial wave characteristic velocity fields in favorable QBO phases. (a),(d) EH eastward-moving equatorial OLR regressed on Kelvin wave equatorial $u$ in the easterly phase; (b),(e) WH westward-moving OLR at $7.5^{\circ} \mathrm{N}$ regressed on WMRG wave equatorial $v$ in the westerly phase; (c),(f) WH westward-moving OLR at $20^{\circ} \mathrm{N}$ regressed on R1 wave $v$ at $8^{\circ} \mathrm{N}$ in westerly phase. Dashed (solid) contours denote negative (positive) OLR, with contours starting from $\pm 0.6 \mathrm{~W} \mathrm{~m}^{-2}$ and with an interval of $0.4 \mathrm{~W} \mathrm{~m}^{-2}$. Shaded areas denote exceedence of the $90 \%$ significance level. The regression value is taken to be 1.5 times the standard deviation peak of the waves. In significant cases, the phase speed $\left(\mathrm{m} \mathrm{s}^{-1}\right)$ is indicated.

There is interesting evidence of enhancement of Kelvin wave activity entering the descending westerly phase for each QBO, with Kelvin wave amplitudes peaking just below the zero wind lines of the westerly phase and then decreasing sharply. This supports the QBO theory that Kelvin waves are driving the descent of the QBO westerly winds. For the WMRG and R1 waves, the corresponding feature with peaking just below the descending easterly phase is less clear, perhaps because the contribution of the two waves to the downward propagation of the easterly region is relatively small. This may explain the observed feature that westerly shear zones show more regular and rapid downward propagation than easterly shear zones. However, there is an interesting feature that during some periods of "stalling" in the descent of the easterlies near $30 \mathrm{hPa}$, WMRG and R1 waves below $30 \mathrm{hPa}$ are less active than in years when there is no such stalling. This suggests that WMRG and R1 waves are playing some role in driving the descent of the QBO easterly winds.

The presence of vertically propagating equatorial waves in the stratosphere has also been found to depend on upper-tropospheric ambient zonal winds and tropospheric forcing. The longitudinal variation of equatorial waves in the upper troposphere, with Kelvin waves being stronger in the $\mathrm{EH}$ and $\mathrm{WMRG}$ and $\mathrm{R} 1$ waves being stronger in the $\mathrm{WH}$, appears to continue into the lower stratosphere, resulting in longitudinal variation in equatorial waves in the lower stratosphere, particularly in the QBO phases in which upward propagation occurs.

Composite propagation features in opposite QBO phases have also been revealed. Waves with large zonal wavelengths and short periods, and therefore faster phase speeds, can propagate more readily. The increased phase speed indicates a filtering of the slow waves. In addition, when the phase of the QBO is not favorable for waves to propagate, their period is shorter, zonal wavenumber is smaller, and phase speed is faster in the lower stratosphere, suggesting a Doppler shifting by the ambient flow and a further filtering of the slow waves. All waves in the upper troposphere and lower stratosphere exhibit downward phase speed but upward group velocity. However, for WH WMRG and R1 waves in the troposphere the sense in the vertical phase speed and group velocity is reversed, suggesting that the waves are initiated in the upper troposphere and then propagate both upward and downward from there. These results are consistent with the previous study of two summers in YHS11 and with wave propagation theory. 
Analysis of the relationship between the lowerstratospheric waves and tropical convection has revealed that tropical convection and convectively coupled equatorial waves act as sources for some waves up to $50 \mathrm{hPa}$ in the stratosphere in the QBO favorable phase and the favorable hemisphere (i.e., the $\mathrm{EH}$ warm water for Kelvin waves in the QBO easterly phase and the $\mathrm{WH}$ for WMRG and R1 waves in the QBO westerly phase). These locations suggest that a tropical convective source is important for the presence of vertically propagating convectively coupled Kelvin waves, whereas, according to YHS07c and as hinted at by the larger WMRG and R1 wave amplitudes over the WH westerly ducts, midlatitude forcing is important for the presence of vertically propagating convectively coupled WMRG and R1 waves. It has also been shown that the connection between the waves and convection varies with season and the wave type, with the Kelvin and R1 waves in winter having the strongest connection with convection. On average, convective signals have smaller phase speeds than those of the lower-stratospheric waves and the convective coupling is much less significant than that in the troposphere (see YHS 07a,b,c). This indicates that, in general, when convectively coupled equatorial waves propagate vertically into the stratosphere, they become disconnected from the space-time patterns of the convective forcing.

While the propagation of equatorial waves is significantly influenced by the phase of the QBO, waveinduced momentum fluxes in the equatorial stratosphere also produce a feedback onto the mean flow. As mentioned above, there is strong evidence of enhancement of Kelvin wave activity entering the descending westerly phase for each QBO. Many recent GCMs that try to internally generate a QBO have difficulty with the downward propagation into the lower stratosphere. Since our study suggests that convectively coupled waves are important in the lowermost stratosphere, it might be hypothesized that part of this difficulty could be the lack of simulated convectively coupled waves. It is known that convectively coupled equatorial waves can be poorly simulated in current tropospheric models (e.g., Ringer et al. 2006; Yang et al. 2009), and this inability may have implications not only for tropical weather and climate but potentially also for stratospheric dynamics.

Another interesting aspect that has been emerged from the analysis is that the intensity of equatorial waves in the upper troposphere seems to be influenced by the QBO phase in the lower stratosphere. In easterly phase the upper-tropospheric WMRG and R1 waves over the eastern Pacific region appear to be somewhat stronger compared with climatology, especially in winter, perhaps due to the accumulation of waves that are unable to propagate upward into the lower stratosphere. In summer this relationship is less clear perhaps due to the large ENSO impact on the wave activity in the western Pacific westerly duct.

There has been increasing evidence over recent years that the state of the lower stratosphere can have an impact on tropospheric flow. However, this is mostly for wintertime at high latitudes (e.g., Baldwin and Dunkerton 2001; Barriopedro et al. 2008; Marshall and Scaife 2009; Gray 2010), and there has previously been little evidence of influence on the tropical troposphere. There has been long-standing observational study of the QBO influence on Atlantic hurricane activity (e.g., Gray et al. 1993; Camargo and Sobel 2010). Some recent studies find that the QBO can influence tropical convection, especially in the tropical Pacific (Garfinkel and Hartmann 2011; Liess and Geller 2012). The present work suggests that an important research for future is the understanding and quantifying of the extent of the stratospheric influence on the underlying tropical troposphere.

Acknowledgments. We thank Tim Dunkerton and an anonymous reviewer for their extremely helpful comments. GYY acknowledges the support of the National Centre for Atmospheric Science (NCAS). GYY and LG are members of NCAS.

\section{REFERENCES}

Alexander, M. J., and D. A. Ortland, 2010: Equatorial waves in High Resolution Dynamics Limb Sounder (HIRDLS) data. J. Geophys. Res., 115, D24111, doi:10.1029/2010JD014782.

Alexander, S. P., T. Tsuda, Y. Kawatani, and M. Takahashi, 2008: Global distribution of atmospheric waves in the equatorial upper troposphere and lower stratosphere: COSMIC observations of wave mean flow interactions. J. Geophys. Res., 113, D24115, doi:10.1029/2008JD010039.

Andrews, D. G., J. R. Holton, and C. B. Leovy, 1987: Middle Atmosphere Dynamics. Academic Press, 489 pp.

Baldwin, M. P., and T. J. Dunkerton, 2001: Stratospheric harbingers of anomalous weather regimes. Science, 294, 581-584.

- and Coauthors, 2001: The quasi-biennial oscillation. Rev. Geophys., 39, 179-229.

Barriopedro, D., R. Garcia-Herrera, and R. Huth, 2008: Solar modulation of Northern Hemisphere winter blocking. J. Geophys. Res., 113, D14118, doi:10.1029/2008JD009789.

Camargo, S. J., and A. H. Sobel, 2010: Revisiting the influence of the quasi-biennial oscillation on tropical cyclone activity. J. Climate, 23, 5810-5825.

Dee, D. P., and Coauthors, 2011: The ERA-Interim reanalysis: Configuration and performance of the data assimilation system. Quart. J. Roy. Meteor. Soc., 137, 553-597.

Dunkerton, T. J., 1990: Annual variation of deseasonalized mean flow acceleration in the equatorial lower stratosphere. J. Meteor. Soc. Japan, 68, 499-508. 
_ 1993: Observation of 3-6 day meridional wind oscillations over the tropical Pacific, 1973-1992: Vertical structure and interannual variability. J. Atmos. Sci., 50, 3292-3307.

_ 1997: The role of gravity waves in the quasi-biennial oscillation. J. Geophys. Res., 102 (D22), 26 053-26 076.

—_, and M. P. Baldwin, 1995: Observation of 3-6-day meridional wind oscillations over the tropical Pacific, 1973-1992: Horizontal structure and propagation. J. Atmos. Sci., 52, 1585-1601.

Ern, M., and P. Preusse, 2009: Wave fluxes of equatorial Kelvin waves and QBO zonal wind forcing derived from SABER and ECMWF temperature space-time spectra. Atmos. Chem. Phys., 9, 3957-3986.

-, - M. Krebsbach, M. G. Mlynczak, and J. M. Russell III, 2008: Equatorial wave analysis from SABER and ECMWF temperatures. Atmos. Chem. Phys., 8, 845-869.

Fujiwara, M., and M. Takahashi, 2001: Role of the equatorial Kelvin wave in stratosphere-troposphere exchange in a general circulation model. J. Geophys. Res., 106, 22763 22780.

Garfinkel, C. I., and D. L. Hartmann, 2011: The influence of the quasi-biennial oscillation on the troposphere in wintertime in a hierarchy of models. Part II: Perpetual winter WACCM runs. J. Atmos. Sci., 68, 2026-2041.

Gehne, M., and R. Kleeman, 2012: Spectral analysis of tropical atmospheric dynamical variables using a linear shallow-water modal decomposition. J. Atmos. Sci., 69, 2300-2316.

Gill, A. E., 1980: Some simple solutions for heat-induced tropical circulations. Quart. J. Roy. Meteor. Soc., 106, 447-462.

Giorgetta, M. A., E. Manzini, and E. Roeckner, 2002: Forcing of the quasi-biennial oscillation from a broad spectrum of atmospheric waves. Geophys. Res. Lett., 29, 1245, doi:10.1029/ 2002GL014756.

Gray, L. J., 2010: Stratospheric equatorial dynamics. The Stratosphere: Dynamics, Transport, and Chemistry, Geophys. Monogr., Vol. 190, Amer. Geophys. Union, 93-107.

Gray, W. M., C. W. Landsea, P. W. Mielke, and K. J. Berry, 1993 Predicting Atlantic basin seasonal tropical cyclone activity by 1 August. Wea. Forecasting, 8, 73-86.

Hitchman, M. H., and C. B. Leovy, 1988: Estimation of the Kelvin wave contribution to the semiannual oscillation. J. Atmos. Sci., 45, 1462-1475.

Holton, J. R., and R. S. Lindzen, 1972: An updated theory for the quasi-biennial cycle of the tropical stratosphere. J. Atmos. Sci., 29, 1076-1080.

Hoskins, B. J., and G.-Y. Yang, 2000: The equatorial response to higher-latitude forcing. J. Atmos. Sci., 57, 1197-1213.

Kawatani, Y., M. Takahashi, K. Sato, S. P. Alexander, and T. Tsuda, 2009: Global distribution of atmospheric waves in the equatorial upper troposphere and lower stratosphere: AGCM simulation of sources and propagation. J. Geophys. Res., 114, D01102, doi:10.1029/2008JD010374.

_ K. Kato, T. J. Dunkerton, S. Watanabe, S. Miyahara, and M. Takahashi, 2010a: The roles of equatorial trapped waves and internal inertia-gravity waves in driving the quasi-biennial oscillation. Part I: Zonal mean wave forcing. J. Atmos. Sci., 67, 963-980.

$\leftarrow,-,-, \ldots$, and,$- 2010 \mathrm{~b}$ : The roles of equatorial trapped waves and internal inertia-gravity waves in driving the quasi-biennial oscillation. Part II: Three-dimensional distribution of wave forcing. J. Atmos. Sci., 67, 981-997.

Kiladis, G. N., M. C. Wheeler, P. T. Haertel, K. H. Straub, and P. E. Roundy, 2009: Convectively coupled equatorial waves. Rev. Geophys., 47, RG2003, doi:10.1029/2008RG000266.
Liebmann, B., and C. A. Smith, 1996: Description of a complete (interpolated) outgoing longwave radiation dataset. Bull. Amer. Meteor. Soc., 77, 1275-1277.

Liess, S., and M. A. Geller, 2012: On the relationship between QBO and distribution of tropical deep convection. J. Geophys. Res., 117, D03108, doi:10.1029/2011JD016317.

Lindzen, R. S., and J. R. Holton, 1968: A theory of the quasibiennial oscillation. J. Atmos. Sci., 25, 1095-1107.

Lott, F., J. Kuttippurath, and F. Vial, 2009: A climatology of the gravest waves in the equatorial lower and middle stratosphere: Method and results for the ERA-40 Re-Analysis and the LMDz GCM. J. Atmos. Sci., 66, 1327-1346.

Marshall, A. G., and A. A. Scaife, 2009: The impact of the QBO on surface winter climate. J. Geophys. Res., 114, D18110, doi:10.1029/2009JD011737.

Radon, J., 1917: Uber die Bestimmung von Funktionen durch ihre Integralwerte längs Gewisser Mannigfaltigkeiten. Ber. Verh. Sächs. Akad. Wiss. Leipzig, 69, 262-267.

Randel, W. J., 1992: Upper tropospheric equatorial waves in ECMWF analyses. Quart. J. Roy. Meteor. Soc., 118, 365394.

, and F. Wu, 2005: Kelvin wave variability near the equatorial tropopause observed in GPS radio occultation measurements. J. Geophys. Res., 110, D03102, doi:10.1029/2004JD 005006.

Ringer, M. A., and Coauthors, 2006: The physical properties of the atmosphere in the new Hadley Centre Global Environmental Model (HadGEM1). Part II: Aspects of variability and regional climate. J. Climate, 19, 1302-1326.

Straub, K. H., and G. N. Kiladis, 2003: The observed structure of convectively coupled Kelvin waves: Comparison with simple models of coupled wave instability. J. Atmos. Sci., 60, 16551668

Suzuki, J., and M. Shiotani, 2008: Space-time variability of equatorial Kelvin waves and intraseasonal oscillation around the tropical tropopause. J. Geophys. Res., 113, D16110, doi:10.1029/2007JD009456.

Takayabu, Y. N., 1994: Large-scale cloud disturbances associated with equatorial waves. Part I: Spectral features of the cloud disturbances. J. Meteor. Soc. Japan, 72, 443-448.

Tindall, J. C., J. Thuburn, and E. J. Highwood, 2006: Equatorial waves in the lower stratosphere. II: Annual and inter-annual variability. Quart. J. Roy. Meteor. Soc., 132, 195-212.

Wallace, J. M., and V. E. Kousky, 1968: Observational evidence of Kelvin waves in the tropical stratosphere. J. Atmos. Sci., 25, 900-907.

Wheeler, M., and G. N. Kiladis, 1999: Convectively coupled equatorial waves: Analysis of clouds and temperature in the wavenumber-frequency domain. J. Atmos. Sci., 56, 374399.

$\longrightarrow,-$, and P. J. Webster, 2000: Large-scale dynamical fields associated with convectively coupled equatorial waves. J. Atmos. Sci., 57, 613-640.

Yanai, M., and T. Maruyama, 1966: Stratospheric wave disturbances propagating over the equatorial Pacific. J. Meteor. Soc. Japan, 44, 291-294.

Yang, G.-Y., B. Hoskins, and J. Slingo, 2003: Convectively coupled equatorial waves: A new methodology for identifying wave structures in observational data. J. Atmos. Sci., 60, 16371654.

,-- , and - , 2007a: Convectively coupled equatorial waves. Part I: Horizontal structure. J. Atmos. Sci., 64, 3406-3423. 
and $-2007 \mathrm{~b}$ : Convectively coupled equatorial waves. Part II: Propagation characteristics. J. Atmos. Sci., 64, 3424-3437.

- —, and —, 2007c: Convectively coupled equatorial waves. Part III: Synthesis structures and their forcing and evolution. J. Atmos. Sci., 64, 3438-3451.

, J. Slingo, and B. Hoskins, 2009: Convectively coupled equatorial waves in high-resolution Hadley Centre climate models. J. Climate, 22, 1897-1919.
B. Hoskins, and J. Slingo, 2011: Equatorial waves in opposite QBO phases. J. Atmos. Sci., 68, 839-862.

Zangvil, A., and M. Yanai, 1980: Upper tropospheric waves in the tropics. Part I: Dynamical analysis in the wavenumberfrequency domain. J. Atmos. Sci., 37, 283-298.

— , and — 1981: Upper tropospheric waves in the tropics. Part II: Association with clouds in the wavenumber-frequency domain. J. Atmos. Sci., 38, 939-953. 